Portland State University

PDXScholar

\title{
The Contribution of Transportation and Land Use to Citizen Perceptions of Livability in Oregon MPOs
}

\author{
Rebecca Lewis \\ University of Oregon \\ Robert Parker \\ University of Oregon
}

Follow this and additional works at: https://pdxscholar.library.pdx.edu/trec_reports

Part of the Transportation Commons, and the Urban Studies Commons Let us know how access to this document benefits you.

\section{Recommended Citation}

Lewis, Rebecca and Parker, Robert. The Contribution of Transportation and Land Use to Livability in Oregon MPOs. NITC-RR-1050. Portland, OR: Transportation Research and Education Center (TREC), 2018. https://doi.org/10.15760/trec.198

This Report is brought to you for free and open access. It has been accepted for inclusion in TREC Final Reports by an authorized administrator of PDXScholar. Please contact us if we can make this document more accessible: pdxscholar@pdx.edu. 

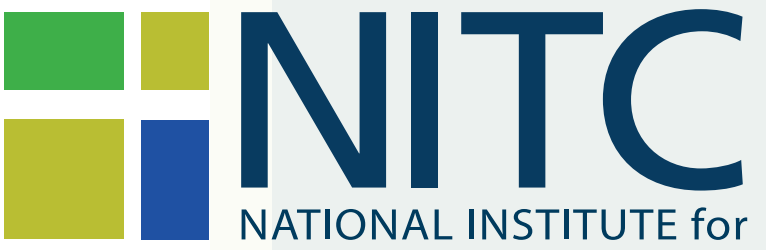

TRANSPORTATION and COMMUNITIES

FINAL REPORT

The Contribution of Transportation and Land Use to Citizen Perceptions of Livability in Oregon MPOs

NITC-RR-1050 a April 2018

NITC is a U.S. Department of Transportation national university transportation center.

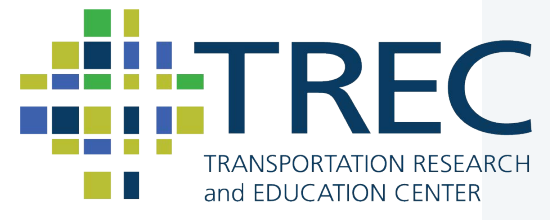





\title{
THE CONTRIBUTION OF TRANSPORTATION AND LAND USE TO CITIZEN PERCEPTIONS OF LIVABILITY IN OREGON MPOS
}

\author{
Final Report
}

NITC-RR-1050

by

Rebecca Lewis, PhD, and Robert Parker, AICP

University of Oregon

$$
\text { for }
$$

National Institute for Transportation and Communities (NITC)

P.O. Box 751

Portland, OR 97207
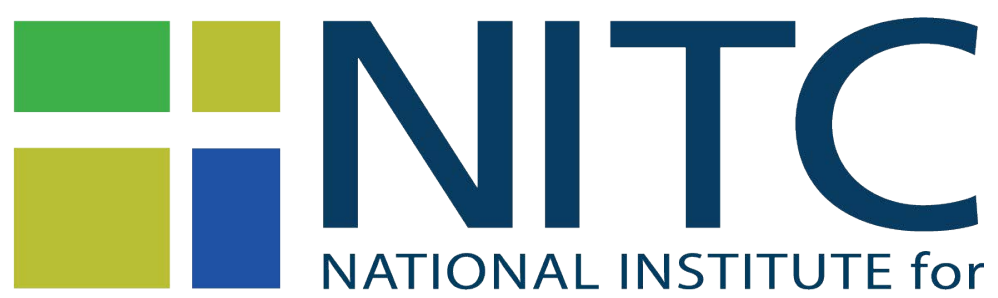

TRANSPORTATION and COMMUNITIES

April 2018 



\begin{tabular}{|l|l|}
\hline Technical Report Documentation Page & 3. Recipient's Catalog No. \\
\hline $\begin{array}{l}\text { 1. Report No. } \\
\text { NITC-RR-1050 }\end{array}$ & 2. Government Accession No. \\
\hline $\begin{array}{l}\text { 4. Title and Subtitle } \\
\text { The Contribution of Transportation and Land Use to Citizen Perceptions of Livability in Oregon } \\
\text { MPOs }\end{array}$ & $\begin{array}{c}\text { 5. Report Date } \\
\text { April } 2018\end{array}$ \\
\cline { 2 - 3 } & 6. Performing Organization Code \\
\hline $\begin{array}{l}\text { 7. Author(s) } \\
\text { Rebecca Lewis and Robert Parker }\end{array}$ & 8. Performing Organization Report No. \\
\hline $\begin{array}{l}\text { 9. Performing Organization Name and Address } \\
\text { University of Oregon, 1209 University of Oregon, Eugene, OR 94703-1209 }\end{array}$ & 10. Work Unit No. (TRAIS) \\
\cline { 2 - 3 } & 11. Contract or Grant No. \\
\hline $\begin{array}{l}\text { 12. Sponsoring Agency Name and Address } \\
\text { P.Otional Institute for Transportation and Communities (NITC) } \\
\text { Portland, OR 97207 }\end{array}$ & 13. Type of Report and Period Covered \\
\cline { 2 - 3 } 15. Supplementary Notes & 14. Sponsoring Agency Code \\
\hline
\end{tabular}

15. Supplementary Notes

\section{Abstract}

Livability is a key focus of integrating transportation and land use planning throughout the United States, and the world. Livability is a concept that has been guiding U.S. Department of Transportation (USDOT) policy since 2009, focusing on six principles including: providing transportation choices, expanding housing location, improving economic competitiveness, improving existing communities, aligning federal policy, and enhancing unique characteristics of communities (USDOT, n.d.). In Oregon, the state's long-range transportation plan (Oregon Transportation Plan) identifies “enhancing livability” as a key outcome. Efficiency and livability are cornerstones of Oregon's Statewide Planning Program, which relies on urban growth boundaries to increase land use efficiency while conserving farm and forestland. The Department of Land Conservation and Development (DLCD), the state agency responsible for overseeing the statewide planning program, uses livability as a guiding principle. Livability is a core element of Statewide Planning Goal 14 (Urbanization) “...to ensure efficient use of land, and to provide for livable communities.” But, as researchers astutely summarized in a 1991 report, "livability is difficult to define, and once defined, to measure" (ECONorthwest, 1991).

While many government agencies at the federal and state level promote livability, little has been done to track and measure it. Oregon has established a policy framework in which land use and transportation decisions are integrated and sets goals for increasing land use efficiency and livability. Government and academic research, however, has not tackled citizen perceptions of how these planning efforts contribute to livability. We seek to fill this research need by exploring the question, "How do citizens understand the connection between transportation and land use planning, and its association with livability?”

The goal of this applied research project is to gain an understanding of how Oregonians in neighborhoods (as defined by ODOT Place Types) within MPOs outside of the Portland metropolitan region perceive livability at the individual, neighborhood and city scale. This study will add to the body of literature on citizen perceptions of livability by focusing on smaller communities outside of Portland - areas that have mostly been overlooked in previous studies. By conducting a targeted survey within selected MPOs across the state, we will gain an understanding of citizen perceptions of livability as it relates to transportation and land use planning. A recently constructed, statewide parcel database and spatial data on transportation investments will be overlaid with survey responses comparing citizen perceptions to existing neighborhoods. This information will provide valuable insight into how cities and state agencies justify investments in transportation infrastructure, which have longterm benefits of creating livable communities.

\section{Key Words}

18. Distribution Statement

No restrictions. Copies available from NITC:

Livability, survey, transportation and land use www.nitc-utc.net

19. Security Classification (of this report)

Unclassified
20. Security Classification (of this page)

Unclassified
22. Price 


\section{ACKNOWLEDGEMENTS}

This research was funded in part by the National Institute for Transportation and Communities (NITC), a program of the Transportation Research and Education Center at Portland State University and a U.S. Department of Transportation University Transportation Center. This research also received funding from the Department of Land Conservation and Development to create the parcel database.

The authors would like to thank Yizhao Yang and Kelly Clifton for guidance in survey design and analysis, and Brook Eastman for GIS analysis. We would like to thank Tara Wiedner and Cody Meyer for input into case study selection and providing data. The authors would like to thank Sadie DiNatale, Tyler Green, Brandon Pike, Seth Thompson and Jenna Whitney for research assistance. The team gratefully acknowledges registered voters who completed the survey and attended focus groups.

\section{DISCLAIMER}

The contents of this report reflect the views of the authors, who are solely responsible for the facts and the accuracy of the material and information presented herein. This document is disseminated under the sponsorship of the U.S. Department of Transportation University Transportation Centers Program and the Oregon Department of Land Conservation and Development in the interest of information exchange. The U.S. Oregon Department of Land Conservation and Development assumes no liability for the contents or use thereof. The contents do not necessarily reflect the official views of the U.S. Government or Oregon Department of Land Conservation and Development. This report does not constitute a standard, specification, or regulation.

\section{RECOMMENDED CITATION}

Lewis, Rebecca and Parker, Robert. The Contribution of Transportation and Land Use to Livability in Oregon MPOs. NITC-RR-1050. Portland, OR: Transportation Research and Education Center (TREC), 2018. 


\section{TABLE OF CONTENTS}

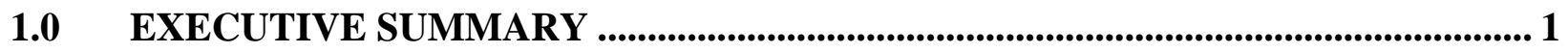

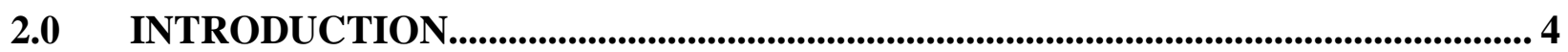

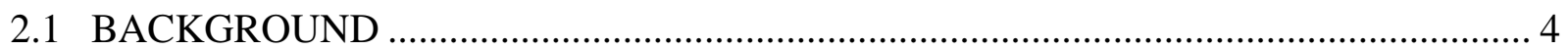

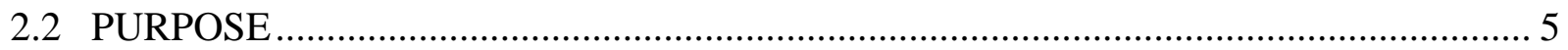

3.0 LITERATURE REVIEW ............................................................................... 7

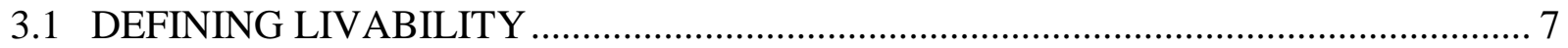

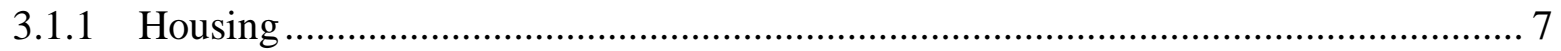

3.1.2 Community Features ..................................................................................... 8

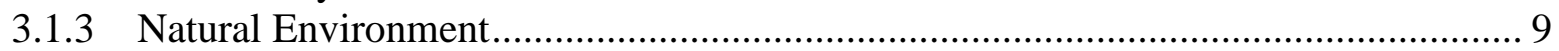

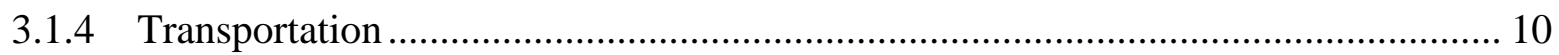

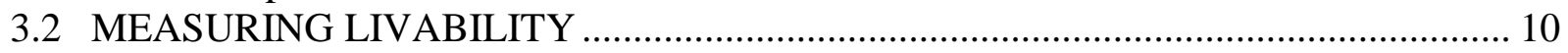

3.2.1 Operational Definitions of Livability................................................................... 11

3.3 PERCEPTIONS OF LIVABILITY ……………................................................... 12

3.3.1 Neighborhood Satisfaction and Urban Form ................................................... 12

3.3.2 Impact of Density............................................................................................ 13

3.3.3 Perceptions of Livability.......................................................................................... 14

3.3.4 Gaps in the Literature.......................................................................................... 15

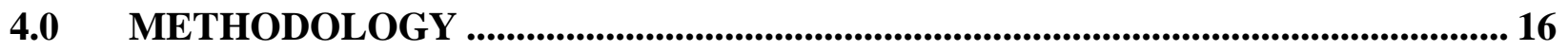

4.1 IDENTIFICATION OF CASE STUDIES.............................................................. 16

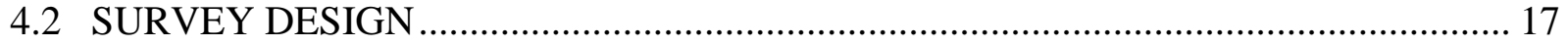

4.2.1 Develop the Sampling Scheme ………............................................................... 17

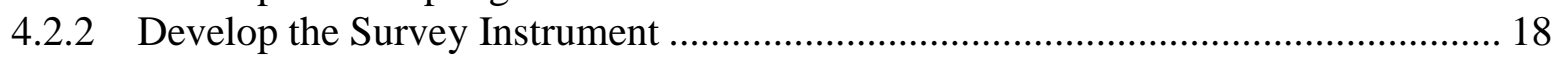

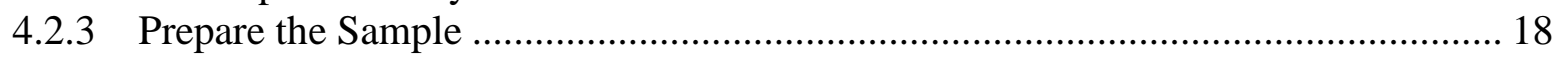

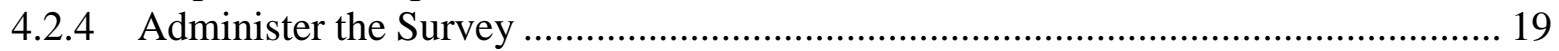

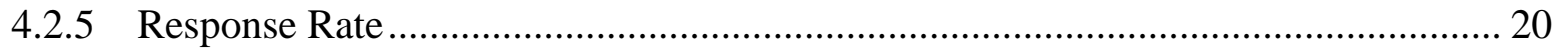

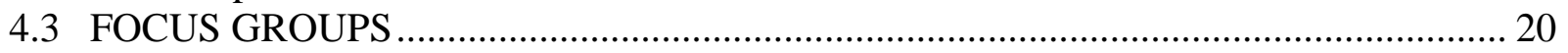

5.0 FINDINGS

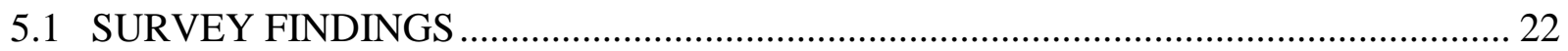

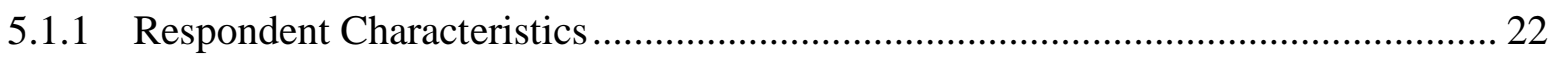

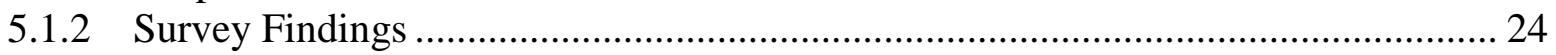

5.1.2.1 General Perceptions of Livability ....................................................................... 24

5.1.3 Influence of the Built Environment on Perceptions of Livability.............................. 27

5.1.4 Influence of Residence and Neighborhood on Perceptions of Livability .................. 33

5.1.5 Influence of Transportation Infrastructure on Perceptions of Livability ………........ 35

5.1.6 Key Survey Findings.................................................................................................. 38

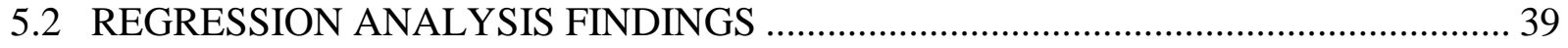

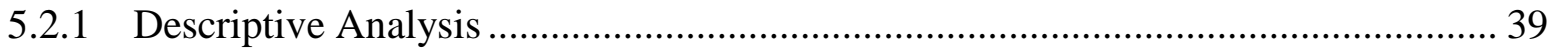

5.2.2 Regression Findings ............................................................................................... 42

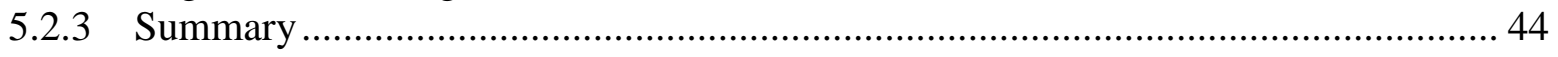

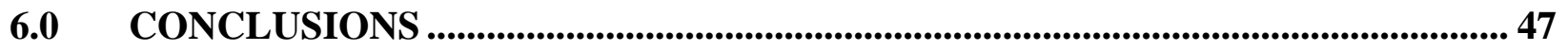

7.0 REFERENCES............................................................................................................. 51

8.0 APPENDIX: SURVEY INSTRUMENT …....................................................................... 57 


\section{LIST OF TABLES}

Table 1: Selected Demographic Characteristics of MPO study areas ..................................... 17

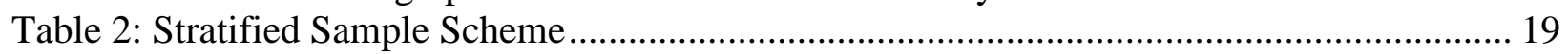

Table 3: Stratified Sample Scheme ...................................................................................... 20

Table 4: Age Distribution of Survey Respondents Compared to the MPO Population 18 and

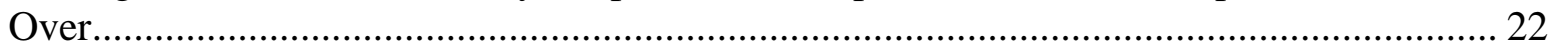

Table 5: Household Income in 2016, Survey Respondents and MPO....................................... 23

Table 6: Household Size of Survey Respondents ............................................................... 23

Table 7: Respondent Satisfaction with House/Home, Neighborhood, City, County, and State... 24

Table 8: Respondent Rating of Importance of Factors for Selecting Current Home or

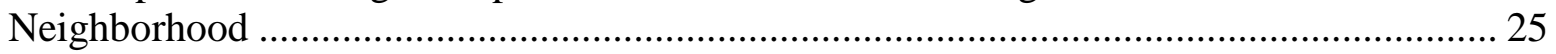

Table 9: Describe Your Ideal Livable Neighborhood in Three Words ..................................... 26

Table 10: Respondent Perceptions of the Livability of Current Home, Neighborhood, City,

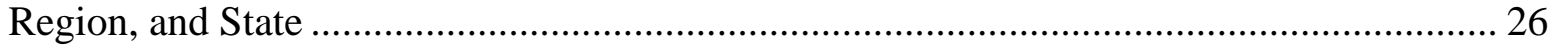

Table 11: Importance of Living Within a 20-Minute Walk of Specific Amenities.................... 29

Table 12: Importance of Built Environment Elements Within a 20-Minute Walk of Ideal Home

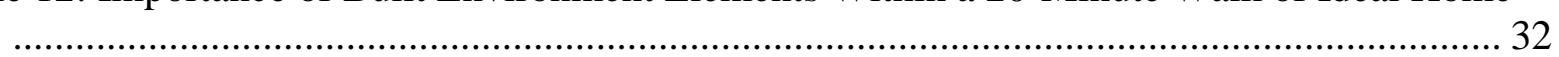

Table 13: Perceived Neighborhood Density Compared to Actual Neighborhood Density .......... 35

Table 14: Respondent Primary Mode Choice for Various Destinations..................................... 36

Table 15: Descriptive Statistics of All Variables................................................................... 41

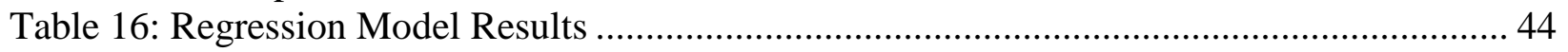

\section{LIST OF FIGURES}

Figure 1: Metropolitan Planning Organizations in This Study ............................................... 16

Figure 2: Satisfaction with Residence and Location by Generation........................................ 25

Figure 3: Respondent Perceptions of the Livability of Current Home, Neighborhood, City,

Region, and State ........................................................................................... 27

Figure 4: Desired Street or Intersection Characteristics in Respondents’ Ideal Neighborhood ... 28

Figure 5: Respondent Perceptions of Level of Foot Traffic: Current Level in their Neighborhood

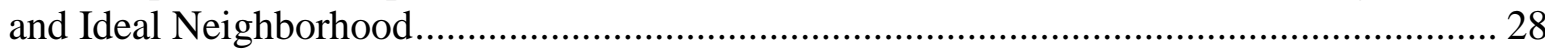

Figure 6: Respondents' Preferred Location of Parking in an Ideal Neighborhood .................... 29

Figure 7: Importance of Living with a 20-Minute Walk to Shops and Services, by Generation . 30

Figure 8: Desired Mix of Land Uses in Respondents’ Ideal Neighborhood, by Generation....... 30

Figure 9: Preferred Housing in Respondents’ Ideal Neighborhood........................................... 31

Figure 10: Respondent Ratings of the Importance that Neighborhood Elements are Visually

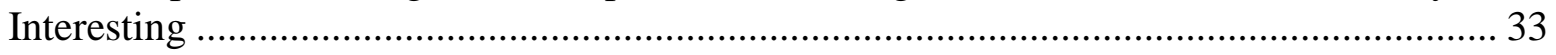

Figure 11: Respondent Description of their Current and Ideal Outdoor Space ........................... 34

Figure 12: Respondents’ Current and Ideal Housing Type .................................................... 34

Figure 13: Transportation Options Respondents Want in their Ideal Neighborhood .................. 36

Figure 14: Respondent Perceptions Whether Their Neighborhood Accommodates all the

Transportation Options They Want .......................................................................... 37

Figure 15: Respondent Agreement with the Statement: "I want my neighborhood to be more

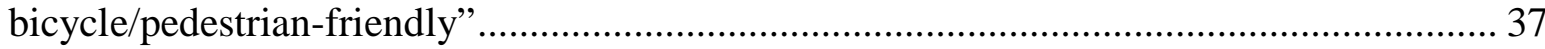




\subsection{EXECUTIVE SUMMARY}

What is livability? How does the built environment influence resident perceptions of livability? Although livability is a broadly used term and a key goal in land use and transportation plans at the state level, it is unclear whether residents think their neighborhoods are livable and what contributes to their perception of livability. The purpose of this project was to understand how Oregonians, in neighborhoods of varying densities and within Metropolitan Planning Organizations (MPOs), perceive livability at the nexus of transportation and land use. We sought to understand how residents define and perceive livability in three different MPOs in the state: Albany, Central Lane, and Rogue Valley. We administered an innovative survey to 3,100 registered voters across the three MPOs. We relied on stratified sampling to obtain a representative sample across different density categories. Our survey instrument included questions about livability, satisfaction, housing choice, and preferred and current characteristics of the neighborhood and accessibility. Based on previous research we examined how individual socioeconomic status, objective neighborhood features, and subjective perceptions of land use and transportation impact perceptions of livability.

This research provides government agencies and community organizations a broader perspective on which characteristics of the built environment add to or detract from livability, or what is sometimes referred to as the "good community." For instance, what does a livable community look like? Is it possible to measure livability objectively? What do residents consider livable and how do these perceptions differ from local and state agency conceptions? Finally, how can local and state governments achieve the objective of creating livable communities? These questions provide the foundation for this research.

Our regression analysis revealed the perceptions were more influential than objective (GIS) or sociodemographic measures. This finding mirrors previous literature which has found that perceptions are the most influential determinants of satisfaction when controlling for sociodemographic characteristics.

Some of our findings offer interesting insights into the determinants of livability. We found that people trade off affordability and livability. When people said that housing affordability was more important in decisions about housing and neighborhood choice, they had more negative perceptions of livability in their neighborhood. But people who prioritize accessibility have a more positive perception of livability. This finding warrants further investigation into the intersection with neighborhood choice and income.

Sociodemographics of individuals and neighborhoods showed interesting and unexpected results. Generation (age) affects perceptions of livability. While Boomers seem to have more positive perceptions of livability overall in the descriptive data, when we controlled for socioeconomic status Millenials saw neighborhoods as more livable than Boomers and Boomers saw neighborhoods as more livable than Generation X. As we expected, higher-income 
neighborhoods were more livable than lower-income neighborhoods, but surprisingly, neighborhoods with a higher share of owner-occupied housing were perceived as less livable. The following table conveys the direction of the influence of objective and subjective measures on perception of livability. This table summarizes findings from descriptive analysis and regression analysis. We organize the table around measures of housing choice, urban form, transportation and amenities (like access to parks and services.)

\begin{tabular}{|c|c|c|}
\hline & Positive & Negative \\
\hline \multirow[t]{4}{*}{$\begin{array}{l}\text { Housing } \\
\text { Choice }\end{array}$} & $\begin{array}{l}\text { Prioritizing accessibility in } \\
\text { housing/neighborhood } \\
\text { choice }\end{array}$ & $\begin{array}{l}\text { Prioritizing affordability in } \\
\text { housing/neighborhood } \\
\text { choice }\end{array}$ \\
\hline & Affordability & \\
\hline & Safety & \\
\hline & Dwelling characteristics & \\
\hline \multirow[t]{4}{*}{ Urban Form } & Sidewalks & Mixed use near homes \\
\hline & Street trees & Density \\
\hline & $\begin{array}{l}\text { Mix of retail, residential } \\
\text { and services }\end{array}$ & $\begin{array}{l}\text { Perception that } \\
\text { neighborhood is too dense }\end{array}$ \\
\hline & Quality housing & \\
\hline \multirow[t]{3}{*}{ Transportation } & Variety of options & $\begin{array}{l}\text { Lack of desired } \\
\text { transportation options }\end{array}$ \\
\hline & Pedestrian options & Driving to work \\
\hline & $\begin{array}{l}\text { Sidewalks, trees, } \\
\text { crosswalks }\end{array}$ & \\
\hline \multirow[t]{2}{*}{ Amenities } & Proximity to parks $(\sim)$ & Proximity to retail \\
\hline & $\begin{array}{l}\text { Proximity to grocery } \\
\text { stores }\end{array}$ & \\
\hline
\end{tabular}

The research has several implications. First, access to transportation options is important in descriptive and regression analysis. More specifically, individuals that reported better access to transportation options across a broad range of measures reported higher ratings of livability. Pedestrian improvements and natural amenities were important to survey respondents. This suggests that to improve livability, local governments seek balanced transportation options including investments in non-auto-centric modes - particularly pedestrian infrastructure. While the results suggest transportation options improve perceptions of livability, it is important to note that those options should not exclude automobile or vehicular options - 86\% of survey respondents indicated this was important in their ideal neighborhood.

The findings, however, suggest challenges with transit. Regression results show a positive relationship between distance to transit stops and livability (e.g., closer transit stops relate to higher perceptions of livability). But, the results suggest that residents may not be tolerant of the densities needed to support alternative modes.

One of the core objectives of this research was to better understand how density relates to perceptions of livability. As a general observation, most respondents did not accurately indicate 
the actual density of the neighborhood they live in. In fact, $28 \%$ indicated the correct density range, while $53 \%$ of respondents indicated perceived densities that were higher than the actual density. Nineteen percent of respondents indicated perceived densities that were lower than the actual density in their neighborhood.

Many communities face ongoing issues with housing affordability, and research increasingly points to zoning codes and NIMBYism as key contributors. The results suggest that density alone does not improve livability and has a negative impact on perceptions of livability. As other studies have shown, density needs to be combined with other services and accessibility to improve livability.

In short, people don't understand density within their neighborhoods. The implications are that local and state government should attempt to educate citizens about what density looks like. Researchers should continue to conduct research that gets at the root causes of these perceptions, which may be more strongly related to income and housing tenure than density. People trade off affordability for livability. Affordable housing policy should focus on making more livable neighborhoods accessible to all income groups. 


\subsection{INTRODUCTION}

This report presents research exploring how Oregonians in small metropolitan regions perceive livability. "Livability" is a term broadly used within the planning discipline and is a central objective within Oregon transportation and land use plans. The term, however, is not defined in state statutes and administrative rules, and different organizations use different criteria to measure livability. In short, communities have broadly embraced livability as a core community development goal, but have not established a means to examine how well they are meeting that goal.

This research project focuses on how the built environment affects residents' perceptions of livability across a broad range of metrics. The research is based on results from a survey of residents in three Oregon Metropolitan Planning Organizations (MPOs) that concentrated on resident perceptions of livability. The survey data is supplemented with land use and socioeconomic data from the study MPOs. Key metrics include housing density, transportation networks, proximity of work and shopping, presence of urban amenities such as parks, diversity of land uses, and social characteristics.

\subsection{BACKGROUND}

In the discipline of urban planning, livability is a term that generally describes a location's desirability or quality of life. The dictionary defines livable as "(1) suitable for living in; habitable; comfortable; (2) worth living; endurable; and (3) able for living; companionable.”1 Livability is the noun form of livable. Planners incorporate livability into community visions and goals. Livability can relate to characteristics such as environmental quality, walkability, open space, economic activity, and the presence of cultural forces and activities. A common characterization of the term is as follows:

"the sum of the factors that add up to a community's quality of life-including the built and natural environments, economic prosperity, social stability and equity, educational opportunity, and cultural, entertainment and recreation possibilities."2

Various definitions and understandings of the term exist at different levels of government and in the nonprofit sector, too. This study seeks to provide a better understanding of how people perceive livability at the individual, neighborhood and city level in Oregon.

In the planning context, the concept of livability is integrated in transportation and land use plans throughout the United States. The concept has been guiding U.S. Department of Transportation (USDOT) policy since 2009 by focusing on six key principles: (1) providing transportation choices; (2) expanding housing locations; (3) improving economic competitiveness; (4)

\footnotetext{
1 "Livable." Dictionary.com. Accessed February 2017. http://www.dictionary.com/browse/livable?s=t.

${ }^{2}$ Partners for Livable Communities. (2017). what is Livability? http://www.livable.org/about-us/what-is-livability
} 
improving existing communities; (5) aligning federal policy; and (6) enhancing unique characteristics of communities. ${ }^{3}$ Moreover, as part of its current list of policy initiatives, the U.S. DOT seeks to pursue coordinated policies that emphasize placed-based decisions and investments, ${ }^{4}$ meaning policy and investment-related decisions occur at the federal level based on general understandings of livability.

The Department of Land Conservation and Development (DLCD), the state agency responsible for overseeing the statewide planning program, uses livability as a guiding principle. Livability is a core element of Statewide Planning Goal 14 (Urbanization):

To provide for an orderly and efficient transition from rural to urban land use, to accommodate urban population and urban employment inside urban growth boundaries, to ensure efficient use of land, and to provide for livable communities. ${ }^{5}$

Efficiency and livability are cornerstones of Oregon's statewide planning program, which relies on urban growth boundaries to increase land use efficiency while conserving farm and forestland. Nevertheless, as researchers astutely summarized in a 1991 report, "livability is difficult to define, and once defined, to measure.”6 Moreover, Oregon’s long-range transportation plan (Oregon Transportation Plan) identifies “enhancing livability” as a key outcome.

\subsection{PURPOSE}

The purpose of this project was to understand how Oregonians, in neighborhoods of varying densities and within MPOs, perceive livability at the nexus of transportation and land use. The genesis of this project derived from earlier work by the research team done for DLCD as part of rulemaking related to House Bill 2254, which required DLCD to develop a simplified pathway for municipalities to amend urban growth boundaries. ${ }^{7}$

This research intends to provide government agencies and community organizations a broader perspective on which characteristics of the built environment add to or detract from livability, or what is sometimes referred to as the "good community." For instance, what does a livable community look like? Is it possible to measure livability objectively? What do residents consider livable and how do these perceptions differ from local and state agency conceptions? Finally, how can local and state governments achieve the objective of creating livable communities? These questions provide the foundation for this research.

\footnotetext{
${ }^{3}$ USDOT. Livability 101: Six Principles of Livability. Retrieved from: https://www.transportation.gov/livability/101

${ }^{4}$ U.S. Department of Transportation. (2015). Livability 101. https://www.transportation.gov/livability/101

${ }^{5}$ OAR 660-0015-0014—Statewide Planning Goal 14, Urbanization.

${ }^{6}$ ECONorthwest. (1991). Urban Growth Management Study. Prepared for the Department of Land Conservation and Development.

${ }^{7}$ In response to the growing complexity of UGB amendment process, the 2013 legislature enacted HB 2254 (codified at ORS 197A and OAR 660-038) to provide for new, simplified methods for growing cities to evaluate the capacity of their UGBs. Livability is used as an evaluation metric to assess impact.
} 
These questions are timely as "many of Oregon's communities are facing new challenges managing the growth that comes with prosperity" (DLCD, 2000). As the population continues to grow in Oregon, cities are becoming denser and is increasing the need for new and updated infrastructure. ${ }^{8}$ Thus, balancing quality of life for residents becomes essential. This project aims to add to the body of literature on citizen perceptions of livability by focusing on smaller communities outside of Portland - areas that have mostly been overlooked in previous studies. Ultimately, this information provides valuable insight into how cities and state agencies justify investments in transportation infrastructure, which have the long-term benefits of creating livable communities.

Our work proceeds as follows: First, we describe previous research on livability, focusing on defining livability, measuring livability, and perceptions of livability. Then, we describe our survey methodology. Next, we present findings from descriptive analysis of our survey results and regression models that examine the impact of sociodemographic, subjective and objective measures. We close with key conclusions gained from this work and propose next steps for future work.

\footnotetext{
${ }^{8}$ Parker, Robert; Lewis, Rebecca; Moore, Terry; Kato Ken (2015). Analysis of Land Use Efficiency in Oregon
} Cities: A Report to the HB 2254 Rules Advisory Committee. 


\subsection{LITERATURE REVIEW}

\subsection{DEFINING LIVABILITY}

In the context of planning and community development, livability is often undefined and rather nebulous. In short, no single agreed-upon definition of livability exists in the planning disciple. To better understand the dimensions of livability, the research team examined existing studies to help in contextualizing the term.

As policies and community plans begin to incorporate livability into their goals and objectives, it becomes important to understand the components that make up a livable community. The research team searched for mentions of the term "livability." From this process, several thematic categories emerged, including (1) housing, (2) community features or attributes, (3) infrastructure, (4) natural environment, and (5) transportation. The results show that each of these thematic categories include one or more potential metrics.

\subsubsection{Housing}

Housing affordability consistently emerged as one of the most important components in deeming a location livable. Baker and Biton (2015) observed that housing costs continue to grow faster than household income, and it is therefore imperative that communities begin to offer housing at higher rates of affordability . Baker and Biton also described the formation of the Partnership for Sustainable Communities (a federal, interagency initiative that promotes livability), in which an essential objective was to generate greater access to affordable housing. According to a study by Harrell et al. (2014), renters identified funding for affordable housing programs as the most important local government investment .

The literature suggests that housing density directly affects perceptions of livability, especially within urban neighborhoods (consider Smart Growth and New Urbanism principles). As discussed by Chapman and Lund (2004) regarding Portland's expansion, dense housing near amenities (sometimes referred to as community features) provides for more livable communities. While livability and density are most often correlated with urban settings, suburban locations are also seeing a push toward densification. Larco (2009) discusses that "it is important to focus on how we are implementing density and how the existing demographic and physical composition of multifamily suburbia might relate to smart growth goals." Godschalk (2007) discusses the relationship between density and design, ultimately stating the quality of place, scale, mix, and connections are of utmost importance regarding livability. In other words, density for density's sake does not contribute to livability - it must be carefully planned for and implemented cautiously.

Design - of buildings and urban areas - is an important component of livability. Ruth and Franklin (2014) discuss the impacts of planning and design implementation: "there is extensive 
empirical evidence, for example, that architecture and planning can shape the economic and social profile of urban environments.” Meanwhile, Mahmoudi, Ahmad and Abbasi (2015) discussed the negative impact of housing and other community features that are not visibly pleasing. For instance, poor design can overshadow the benefits of housing density or stigmatize housing affordability.

Harvey and Aultman-Hall (2016) note that further research on livability and housing needs to include quantitative (GIS) and qualitative assessment. While there is still much to understand, it can be posited that housing affordability, design, and density are connected. To generate truly livable neighborhoods, particularly in growing communities, each of these three aspects must work together.

\subsubsection{Community Features}

Research into livability frequently cites community features as being important. Sometimes called urban amenities or streetscapes, community features include elements such as sidewalks, street trees, lighting, crosswalks, benches and other elements of the street environment.

Community features such as lighted bike paths along a river, a covered bus-stop shelter along a street or drinking fountains in a downtown neighborhood are becoming the norm for livable places. In fact, livable places are often judged by the amount and diversity of community features (amenities) they have (Balas, 2004). Not just quantity, but quality of community features is important. For instance, residents accustomed to historic architecture and intimate living and working spaces have vastly different notions of livability than those with more modernistic, grungy, or simple design preferences (Pojani and Stead, 2014). Accordingly, communities need to consider the features they employ: "adopt a narrative that resonates by leveraging historic, cultural or other unique attributes of your community that tend to unite people” (Guzman and Douglas, 2015).

Community features influence how people interact with others, another heavily cited component of livability. Silverstein, Johns, and Griffin (2008) discuss community features in relation to elder populations: "elder livability refers to the features of a local community that support older residents who wish to age in place, such as the presence of culturally appropriate services, good transportation options for non-drivers, safe neighborhoods, and affordable housing.” Guzman and Douglas (2015) reiterate this by stating that a strategy toward livability is to build individual relationships. Human connections exist and flourish across a broad set of sectors, career and life paths: "foster connections with people in each sector, such as a business person or a faith-based leader, who will assume the role of a Livable Communities champion by leveraging their networks to spread the world." With the importance of fostering these connections, having the ability to do so daily is essential for elderly populations. Heatwole-Shank and Cutchin (2016) found that daily interactions are a key piece of contributing to positive connotations of livability regarding communal features.

Finally, community features regarding natural landscapes are of importance within the realm of livability. Jim (2003) found that legislators are committed to implementing and protecting trees and other environmental features as an element of livable communities. Planners need to be aware of stressing the importance of individual features too heavily, however. While community 
features and amenities are important, weighing these too heavily on a single feature can come at the detriment of the community, especially if community members are not able to voice their preferences (Lewis and Donald, 2010).

In summary, the literature identifies several dimensions of community features: physical (such as street amenities or design elements), social (human interactions), and natural environment (treelined streets or parks). These dimensions' overlap because community features are meant to be shared and to strengthen each other. For example, a bike path (physical) reinforces the river (natural); street trees (natural) reinforces sidewalk benches (natural); playground features in an urban plaza (physical) reinforces interaction and the creation of familiar strangers (social). While a single feature can create amenity, diverse features enhance livability.

\subsubsection{Natural Environment}

Elements of the natural environment such as natural open spaces, water, air quality, and green infrastructure contribute to community livability. Clean drinking water and air, as well as access to healthy landscapes, are also related to people's sense of livability. People do not desire to live in contaminated places. In fact, one author notes that "landscape architecture will be crucial to humanize our cities and create warm and friendly environments where residents can find recreational space” (Grau, n.d.). Accordingly, the need for a healthy, natural environment is intrinsic to generating livable neighborhoods for everybody.

The relationship between livability, the natural environment, and equity are hard to tease apart. One author points out that access to open space and parks are somewhat dependent on residents' nativity status, finding that native-born residents of the United States are 7\% more likely then foreign-born residents to live in neighborhoods with recreation options (Li, 2012). Rector (2006) found that wealthier households have better access to idealized locations in a community, where proximity to the natural environment is idealized and immigrants tend to be poorer on average. ${ }^{9}$

$\mathrm{Li}$ also states that more foreign-born residents live within a half block of railroads, airports, and four-lane highways, which places a disproportionate strain on those communities in terms of air and noise pollution. In this respect, "tensions between livability and ecology result in the 'green cities conflict,"” which arises from competing beliefs in the primacy of the natural versus the built environment (Duany et al., 2000; Beatley, 2000; Beatley and Manning, 1997). Godschalk (2004) explains that these tensions between livability and environmental equity result in the "gentrification conflict," where land use decisions negatively and disproportionately affect lower-income households.

In summary, natural features are important to individuals' perception of livability. Livability, physical space, and social concerns are connected. It is necessary to keep in mind that not all residents share equal access to livable places; clean, safe ecology and healthy, natural elements do not exist in all neighborhoods and communities.

\footnotetext{
9 "First-generation immigrants and their families, who are one-sixth of the U.S. population, comprise one-fourth of all poor persons in the U.S.” Rector, Robert. (2006). Immigration and Poverty in the United States: A Book of Charts. The Heritage Foundation.
} 


\subsubsection{Transportation}

Transportation is frequently associated with livability, either through mention of traffic congestion, safer streets, transportation alternatives and modal choices, or even the impact new technology could have on transportation systems into the future. Appleyard et al. (2017) write that, “... livability has been identified as an important outcome of strategies to promote transportation and land use integration, but little guidance exists on what livability actually is, how to measure it, or how transportation and land use integration strategies can promote it." Appleyard et al. did a multiyear study on livability literature, theory and practice, followed by an extensive study of quantitative and qualitative methods of over 350 transit corridors to conclude, “... livability can be seen as an organizing principle for determining when and how to deploy integrated transportation and land use planning strategies.” Livability opportunities are qualityof-life outcomes, particularly around transit.

Policy debates around the best strategies to accomplish these transportation goals of improving mobility, access, and options often discuss decreasing reliance on car dependency, which is a commonly cited goal of livability. Planners have also focused on creating more walkable communities. Simply said, but not simply accomplished, walkable communities and neighborhoods require robust levels of "livability-guided" land use and transportation initiatives. Taking steps to improve the walkability of neighborhoods requires practitioners to be cognizant of the three Ds: (increasing) density, (promoting) diversity, and (integrating) design (Appleyard et al., 2017).

Like other elements of livability, transportation is context dependent. Mekuria et al.(2017) concluded that "improving transit mobility and the comfort and encouragement of pedestrians and bicyclists to access a larger service area than traditionally attributed to transit produces the highest livability and increases alternatives for the traveler.” By contrast, in rural communities "livability may involve improving regional mobility and safety on rural highways connecting workers to jobs, and economic development” (Pokharel et al., 2014).

In summary, livability and transportation are closely connected. The key dimensions are mobility and access. Like housing, we all require transportation to live and function in our modern dayconstructed communities. While alternative modes of transportation are becoming increasingly important, particularly for urbanizing locales, rural and small communities still rely on the automobile. Some research suggests that reduction in automobile use increases livability (Chinnam and Murat, 2016).

\subsection{MEASURING LIVABILITY}

Like the terms "sustainability" and "resilience," livability is somewhat of a buzzword. Public agencies and academics use the term extensively with many assumed connotations (Vanzerr, 2011; USDOT, 2012). Yet, as is the case with many buzzwords, the actual definition of livability is unclear (Ferrell, 2016) and is dependent on context. The planning community seems to share a general understanding that livable communities are ones that people want to live in. Beyond this rather obvious fact lies a hazy area where no clear or concrete distinctions are drawn. 
As livability becomes an increasingly important term in planning theory and practice, a clear interpretation of the term is ever more urgent. Operationalizing the concept of livability is necessary if communities want to work toward common goals and when evaluating whether they are getting closer to those goals. Before exploring the concept of livability, it is worthwhile to explore a basic framework for defining and measuring concepts and discus the operational definitions that exist to date.

Central to the idea of empirical research is measurement. In a statistical analysis sense, measurement is the assignment of numbers to a phenomenon that one is interested in analyzing. Often the phenomenon of concern is a broad one that does not have any single, accepted measure (e.g., patriotism, altruism, livability). Thus, to do empirical work about important concepts researchers must operationalize them (i.e., they must define the process they will use to measure the concepts).

A standard framework for measurement holds that concepts are measured indirectly through indicators specified by operational definitions. ${ }^{10}$ Operational definitions are statements that specify how a concept will be measured, and metrics refer to things that can be measured directly and are linked to a concept through an operational definition. The key concept this research addresses is "livability.” While different organizations identify various metrics for measuring livability, it is surprising how broadly the term is used and how little structure is provided in planning documents.

\subsubsection{Operational Definitions of Livability}

Livability is a concept that is largely undefined by state and federal agencies, and literature does not suggest any consensus about how to measure it. Without an agreed-upon operational definition, there are no set metrics or indicators that serve to classify the livability of communities. This, however, does not mean that people, organizations, and governments do not try.

Several federal agencies have proposed dimensions (key principles) that seek to create or enhance livability. Moreover, organizations such as the American Association of Retired Persons (AARP) and livability.com developed methodologies and indices that rank places by their livability. In fact, the AARP contextualizes livability, stating that, "A livable community is one that has affordable and appropriate housing, supportive community features and services, and adequate mobility options, which together facilitate personal independence and the engagement of residents in civic and social life" (Kihl et al., 2005). Finally, individuals and groups tend to hold their own notions of what makes a place livable based on tastes and preferences.

Accordingly, while the concept of livability can be multidimensional, the term invokes common themes or metrics. Indices such as AARP's or those developed by livability.com perhaps have some of the more robust methodologies for measuring these themes, as they operate on a national level, to compare the quality of place at different geographic scales (neighborhood, city, country, etc.). Well used by individuals and mimicking policies geared toward creating livable places, these methodological approaches use both quantitative and subjective measures to rate, score, or

\footnotetext{
${ }^{10}$ Basic Methods of Policy Analysis and Planning 3rd Edition. Patton, Sawicki, and Clark, 2012.
} 
prioritize communities based on tangible and intangible elements of place. In view of this, while these indices do not pose an official definition, they do offer an interesting approach to operationalizing the concept.

Appleyard et al. (2014) observed the danger of having one definition to apply to all circumstances involving livability: "livability in a just society requires all individuals be assured equal access to such opportunities. Rather than one, monolithic definition of livability, there is a need for a theoretical moral basis to measure, understand and judge activity toward livability achievement through a set of clear, concise and easily applicable livability ethics.” The ethics discussed by Appleyard et al. are similar to the livability principles outlined by the Partnership for Sustainable Communities (see Appendix D).

Nonetheless, the term's use in a planning context affects important aspects of people's lives and thus warrants operationalization. For example, local, state, and federal governments allocate public funding to projects and initiatives under the guise of promoting "livable communities.” It is this hazy understanding of livability that prompts researchers in the planning and public policy fields to ask: How do people make determinations of a livable community? Why do certain places feel more, or less, livable to certain people? Do different individuals experience livability in the same way? Answering these questions could help generate metrics and criteria, allowing for a better allocation of funding and improved planning practices in general.

\subsection{PERCEPTIONS OF LIVABILITY}

The core of this research focuses on resident perceptions of livability; more specifically, how the built environment affects perceptions. Consistent with our research questions, we focus our literature review around three core themes: (1) neighborhood satisfaction and urban form: (2) impact of density; and (3) livability.

\subsubsection{Neighborhood Satisfaction and Urban Form}

There is a robust and extensive body of literature on neighborhood satisfaction. Dozens of studies have considered the determinants of neighborhood livability (Buys and Miller, 2012; Cook, 1988; Grogan-Kaylor et al., 2006; Gruber and Shelton, 1987; Hur and Morrow-Jones, 2008; Hur et al., 2010; Lu, 1999; Parkes et al., 2002). As Permentier et al. (2011) describe, the literature describes three primary groups of determinants: (1) individual/household sociodemographic characteristics; (2) subjective evaluations of neighborhood attributes; and (3) objective characteristics of the neighborhood.

Researchers have found that subjective evaluations are more important than objective attributes and sociodemographic characteristics (Lu, 1999; Parkes et al., 2002; Campbell et al., 1976; Carp et al., 1976; Galster, 1987). Lee et al (2017) examine the relationship between perceived and objective attributes to neighborhood satisfaction, confirming the finding that subjective evaluations are stronger than objective evaluations.

The primary factors that have been found to positively influence neighborhood satisfaction are safety, quietness, neighborhood ties and attractiveness (Mouratidis, 2017; Lovejoy et al., 2010). 
In studying objective factors, several scholars have examined how urban design and urban form affect neighborhood satisfaction. For example, Cao (2015) examines land use mix, density, and street connectivity. In examining how neighborhood design affects satisfaction in the Twin Cities, Cao finds that land use mix is insignificant, higher density is negative, and street connectivity is positive and most influential.

Some studies of neighborhood satisfaction have sought to understand how perceptions vary across different metropolitan areas (Yang, 2008) or types of neighborhoods (Mouratidis, 2017; Lovejoy et al., 2010; McCrea, Shyy and Stimson, 2013). Lovejoy et al. finds that respondents from traditional neighborhoods are more satisfied with location and house characteristics than respondents from suburban neighborhoods. McCrea, Shyy and Stimson show similar levels of satisfaction across neighborhood types with respect to access to services, the natural environment and social environment.

The most common data collection method is surveys but the regression techniques vary. Some scholars use ANOVA (McCrea, Shyy and Stimson, 2013); some use ordinal regression models (Buys and Miller, 2012); some use ordered logit regression models (Lovejoy et al., 2010; Howley et al., 2009); and some use multilevel regression (Yang, 2008; Grogan-Kaylor et al., 2006). Mouratidis (2017) relies on triangulation from surveys, longitudinal analysis, and interviews to validate results.

\subsubsection{Impact of Density}

In this study, we are interested in how density affects satisfaction and perceptions of livability. Research on the impact of density on satisfaction is mixed. Research on the impact of density on livability is limited and discussed in the next section.

Some scholars have studied how density impacts neighborhood satisfaction. The research is varied. Several scholars find that high density is detrimental to life satisfaction (Cao, 2015; Bramley et al., 2009; Cook, 1988; Rodgers, 1981; McCulloch, 2012; Van Dyck, Cardon, Deforche and De Bourdeaudhuij, 2011). Other studies show that high density is not detrimental to satisfaction (Adams, 1992; Arundel and Ronald, 2017; Howley et al., 2009; Kearney, 2006). Yang (2008) shows that the impact of density on satisfaction varies based on context, finding that density positively influences satisfaction in some metropolitan areas like Portland but negatively influences satisfaction in lower-density areas like Charlotte, N.C.. Other scholars have found that perception of environmental quality dos not vary across density ranges, finding that "people trade off elements of their environment against each other for overall neighborhood satisfaction” (Walton et al., 2008, p. 418).

Some scholars examine the relationship between density and amenities or services. McCrea and Walters (2012) find that residents trade off resistance to density for neighborhood amenities and services. Allen (2016) also finds that services play a role in contributing to "quality of life" in higher-density neighborhoods in Auckland. Bramley (2006) found that urban residents trade off enhanced services and amenities for density against detached suburban houses. Lovejoy et al. (2010) also show that characteristics that promote accessibility positively influence neighborhood satisfaction when densities are similar. 
Some scholars have looked exclusively at high-density residents. Buys and Miller (2012) examined inner-urban, higher-density neighborhoods in Australia, examining satisfaction with the dwelling, neighborhood and neighbors. Buys and Miller find that acceptance of density depends on dwelling design, noise and safety. Yang and O’Neill (2013) examine attitudes towards compact, mixed use by surveying residents in a New Urbanist community. Haarhoff, Beattie and Dupuis (2016) examine how density impacts livability in Auckland by examining three case studies of high density. The authors used interviews to understand how the perception of neighborhood affects livability. Haarhoff, Beattie and DuPois found that the interviewees were satisfied with high-density neighborhoods, but affirmed the findings of Walton et al. (2008), McCrea and Walters (2012), and Allen (2016) regarding the tradeoff between density and services. But, Haarhooff, Beatttie and Dupois acknowledge the limitations of their work. Because the authors only look at high-density neighborhoods, it is not possible to compare highdensity to low-density perceptions.

Bonnes, Bonaiuto and Ercolain (1991) examine how crowding (density) impacts satisfaction by interviewing people in different types of neighborhoods in Rome. The authors used factor analysis and regression analysis to examine how sociodemographic characteristics and factors summarizing spatial density influence satisfaction. The authors found that the neighborhood type impacts satisfaction but not the evaluation of crowding, and that length of residence affects satisfaction but not the level of crowding perceived by respondents. Further, the authors found that age and socioeconomic status were most related to satisfaction.

\subsubsection{Perceptions of Livability}

While the literature more frequently considers neighborhood satisfaction, a few scholars make reference to livability. In some instances, neighborhood satisfaction is used as a proxy for livability (Mouratidis, 2017). In others, different metrics are used to examine livability (Chen et al., 2013). Additionally, some scholars have examined how street characteristics affect livability (McAndrews and Marshall, 2018).

Two previous studies have examined how density relates to livability. Mouratidis compares livability in compact and sprawled neighborhoods in Oslo, Norway, by examining neighborhood satisfaction as a proxy for livability. Mouratidis considers how public transport, accessibility to the city center and land use mix impact neighborhood satisfaction as well. Mouratidis finds that higher density leads to higher neighborhood satisfaction. The author suggests that it important to integrate density with other aspects like land use mix and public transportation to positively influence livability. Howley et al. (2009) also uses neighborhood satisfaction as a proxy for livability. Howley et al. examines the relationship between density and satisfaction in the central city in Dublin, Ireland. The authors find that density is not the source of dissatisfaction, but environmental quality, noise, traffic, and lack of services and facilities cause dissatisfaction in dense neighborhoods.

Some studies have asked about perceptions of livability directly. Li (2012) examines how perceptions of livability differ between native and foreign-born residents. Li finds that singlefamily neighborhoods, cleanliness, and newer housing are seen as more livable. In examining 
demographics, racial minorities tend to rate their neighborhoods as less livable, while some foreign-born residents from particular countries (such as Europe, Latin America, and Middle Eastern countries) rate their neighborhoods as more livable.

Chen et al. (2013) examines livability and neighborhood satisfaction in China, focusing on how satisfaction varies by income status. The authors used random sampling by district to obtain a representative sample from different spatial units. Chen et al. examined residential location, housing characteristics and satisfaction while controlling for sociodemographic characteristics. In this study, Chen et al. define livability by examining surrounding land uses and designating neighborhoods in industrial zones as less livable. The authors found that neighborhood satisfaction varies with income, as lower-income groups are less satisfied with their neighborhoods. Further, the authors find that lower-income groups live in less livable (more industrial) neighborhoods.

More recently, scholars have examined the relationship between street design and livability. McAndrews and Marshall (2018) surveyed neighbors of 10 arterials in Denver to understand how roads affect perceived livability. The authors found that arterials that are perceived as vibrant are positive associated with livability. Thus, the authors conclude "livable arterials are those with commercial establishments that residents enjoy frequenting and those that residents perceive to be accessible to public transportation, bicycles, and pedestrians” (pg. 41).

\subsubsection{Gaps in the Literature}

A robust literature regarding neighborhood satisfaction points to three types of variables that are important to predicting neighborhood satisfaction: (1) subjective measures of urban form; (2) objective measures of urban form; and (3) sociodemographic control variables. Lovejoy et al. (2010) provides a detailed list of variables that have been examined in neighborhood satisfaction studies and summarizes the findings and direction of relationships. Density has been considered in a few of these studies. Most studies show a negative relationship between density and livability, but the results are mixed. Most studies of neighborhood satisfaction are survey-based but a few studies rely on interviews and focus groups. A few recent studies have sought to understand how neighborhood satisfaction varies by neighborhood type, examining city center vs. suburbs, or New Urbanist neighborhood vs. conventional neighborhood. There are numerous studies of neighborhood perception, but far fewer studies of neighborhood livability.

We seek to fill a gap in the literature by focusing on how perceptions of livability vary by density categories in smaller MPOs in Oregon. While there have been several comparative studies of different neighborhood types, there have been few studies of rural communities. Further, we focus on subjective evaluations of livability rather than neighborhood satisfaction. 


\subsection{METHODOLOGY}

\subsection{IDENTIFICATION OF CASE STUDIES}

The literature review revealed that much of the research on livability and neighborhood preference has focused on larger metropolitan regions. The authors intentionally study smaller metropolitan regions to address that gap in the literature. Federal planning law (49 U.S.C. 5303) requires urbanized areas with a population of 50,000 or more to undertake a continuing, comprehensive, and cooperative (3C) multimodal transportation planning process. MPOs are created and designated to carry out the metropolitan transportation planning process.

This project focuses on Oregon MPOs, excluding the Portland MPO. These regions have populations between 50,000 and 300,000 and generally exhibit suburban and small-city development patterns. The research focused on three geographic regions: Albany , Central Lane , and Rogue Valley (see Figure 1). Researchers chose these three MPOs due to their variation in size and residential density.

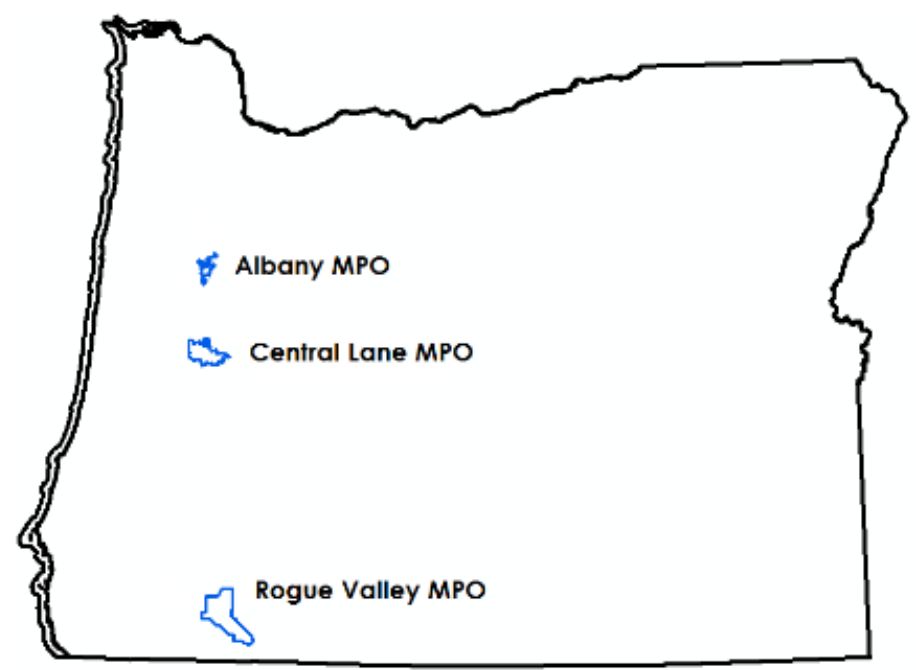

Figure 1: Metropolitan Planning Organizations in This Study

Source: The MPOs sampled in this study include Albany, Central Lane, and Rogue Valley.

Table 1 shows selected demographic characteristics of the MPO study areas and statewide. The data indicate that, while differing in size, the MPOs are similar across most variables with a few exceptions. Central Lane MPO has a higher percentage of individuals 25 and over with degrees, a lower percentage of single-family residences, and a lower percentage of people who drove alone to work - this is likely due to the presence of several higher-education institutions in the region, including the University of Oregon. 
Table 1: Selected Demographic Characteristics of MPO study areas

\begin{tabular}{|c|c|c|c|c|}
\hline Indicator & Albany & Central Lane & $\begin{array}{l}\text { Rogue } \\
\text { Valley }\end{array}$ & Oregon \\
\hline Population & 57,368 & 219,850 & 139,205 & $3,939,233$ \\
\hline \multicolumn{5}{|l|}{ Age } \\
\hline$<20$ & $28 \%$ & $24 \%$ & $25 \%$ & $18 \%$ \\
\hline $20-64$ & $59 \%$ & $63 \%$ & $57 \%$ & $66 \%$ \\
\hline $65+$ & $13 \%$ & $13 \%$ & $18 \%$ & $16 \%$ \\
\hline \multicolumn{5}{|l|}{ Race } \\
\hline White & $81 \%$ & $80 \%$ & $82 \%$ & $77 \%$ \\
\hline Latino & $12 \%$ & $10 \%$ & $11 \%$ & $12 \%$ \\
\hline All others & $7 \%$ & $10 \%$ & $7 \%$ & $11 \%$ \\
\hline \multicolumn{5}{|l|}{ Educatonal Attainment } \\
\hline Bachelor's or higher (age 25+) & $24 \%$ & $33 \%$ & $28 \%$ & $31 \%$ \\
\hline \multicolumn{5}{|l|}{ Housing } \\
\hline Percent single-family & $70 \%$ & $62 \%$ & $69 \%$ & $64 \%$ \\
\hline \multicolumn{5}{|l|}{ Commute } \\
\hline Percent drove alone & $90 \%$ & $67 \%$ & $76 \%$ & $71 \%$ \\
\hline
\end{tabular}

\subsection{SURVEY DESIGN}

A mixed-mode survey of households in the three study MPOs was one of the primary data collection tools for this study.

The survey process proceeded as follows: (1) develop a sampling methodology/scheme; (2) develop the survey instrument; (3) obtain the sample frame; (4) pull the sample; (5) administer the survey; and (5) analyze the results. This appendix describes steps 1 through 5 in detail. To develop and administer the survey, the research team used the "Tailored Design Method for Mail and Internet Surveys” developed by Dr. Don Dillman (Dillman et al., 2014).

\subsubsection{Develop the Sampling Scheme}

The research questions drove the process of developing the sampling scheme.

- How do citizens perceive and define livability?

- How do different racial, ethnic and income characteristics relate to citizen perceptions?

- What terms do citizens use to describe livability?

- How do these terms relate to objectively defined measures of the built, social and economic environment?

- Which aspects of livability are most important to citizens?

- What are the key transportation, land use, social and economic characteristics of livability?

- How do definitions of livability differ across place types (described above), cities and MPOs across the state?

The research team was interested in several dimensions of representativeness in the sample: by MPO study area; by development type; and by density class. The principal investigators then developed a sampling methodology to capture a representative sample of Oregonians among the three MPOs . These three MPOs were selected due to their variability of neighborhood densities (defined by Transit Analysis Zones) with consultation from DLCD and ODOT. 
Samples were selected across five categories of neighborhood densities (housing units per acre) using Census data in addition to voter registration records. Density categories included: 0 to 0.99 housing units/acre, 1.00 to 3.00 housing units/acre, 3.01 to 6.00 housing units/acre, 6.01 to 12.00 housing units/acres, and 12.01 and more housing units/acre. Because voters were unevenly represented across the density categories, the research team used a hybrid approach to identify the number of participants by group based on the objective of receiving 30 surveys per group with an expected response rate of $20 \%$. Thus, we first computed proportional representation for all categories, then adjusted the low and high categories to obtain at least 120 participants for each density group.

\subsubsection{Develop the Survey Instrument}

- The research team developed the survey instrument based on (1) the research objectives, (2) previous surveys developed by the principal investigators, and (3) conceptual frameworks found in related academic literature. The survey included 38 questions organized in five sections:

- Questions about respondent perceptions of livability;

- Questions about how land use and transportation factors influence perceptions of livability at the neighborhood level;

- Questions regarding preferences for livability as it relates to participants' residence and neighborhood;

- Questions about transportation options; and

- Questions about respondent characteristics.

The survey was field tested on approximately 30 subjects to identify any areas where language was unclear or ambiguous, questions respondents found difficult, and the length of time it took to respond to the survey. The field test resulted in several modifications to the final survey instrument.

\subsubsection{Prepare the Sample}

Oregon voter registration lists were used as the sample frame. The research team obtained lists from Benton, Lane, Linn, and Jackson counties - the counties that included portions of the study area MPOs. Table 2 shows the sampling scheme. 
Table 2: Stratified Sample Scheme

\begin{tabular}{lrr} 
Albany & $\begin{array}{c}\text { Registered } \\
\text { Voters }\end{array}$ & $\begin{array}{c}\text { Number } \\
\text { Sampled }\end{array}$ \\
Rural $(>=0$ and $<1)$ & 2,648 & 120 \\
Low $(>=1$ and $<3)$ & 12,085 & 382 \\
Medium $(>=3$ and $<6)$ & 9,426 & 378 \\
Medium-High $(>=6$ and $<12)$ & 1,756 & 120 \\
High $(>=12)$ & - & - \\
\hline & $\mathbf{2 5 , 9 1 5}$ & $\mathbf{1 , 0 0 0}$ \\
\hline Eugene/Springfield & & \\
Rural $(>=0$ and $<1)$ & 8,601 & 120 \\
Low $(>=1$ and $<3)$ & 51,592 & 245 \\
Medium $(>=3$ and $<6)$ & 61,762 & 365 \\
Medium-High $(>=6$ and $<12)$ & 15,403 & 150 \\
High $(>=12)$ & 3,373 & 120 \\
\hline & $\mathbf{1 4 0 , 7 3 1}$ & $\mathbf{1 , 0 0 0}$ \\
\hline Medford & & \\
Rural $(>=0$ and $<1)$ & 11,183 & 120 \\
Low $(>=1$ and $<3)$ & 38,313 & 371 \\
Medium $(>=3$ and $<6)$ & 34,553 & 389 \\
Medium High + High $>=6$ & 6,190 & 120 \\
\hline & $\mathbf{9 0 , 2 3 9}$ & $\mathbf{1 , 0 0 0}$ \\
\hline
\end{tabular}

The sample was pulled by merging land data into the address files. Samples were selected by generating random numbers and sorting the list by each strata from lowest to highest random numbers. The first $\mathrm{n}$ records were selected based on the number of desired samples from each strata.

\subsubsection{Administer the Survey}

The survey was administered to 3,100 randomly selected registered voters across the study MPOs and household density categories. The research team used a mixed-mode methodology that included options for mail or online responses. Those selected to participate received a postcard with the opportunity to take the survey online via Qualtrics. A paper survey (that included a link to the Qualtrics survey version) was mailed a week later to those who had not taken the online survey yet. CPW kept track of participants who completed the survey via a unique code tied to the respondent and their address. Respondents were instructed to enter or record this unique code prior to taking/submitting their survey. Finally, reminder notifications were also distributed.

Survey respondents also had the option to opt into a drawing for an opportunity to win a gift certificate; this provided incentive to participate, although residents did not need to participate in order to enter. 


\subsubsection{Response Rate}

The survey was administered to 3,100 registered voters in Albany, Central Lane and the Rogue Valley using a mixed-mode method. Of the Oregon population aged 18 or older, $87 \%$ is registered to vote. ${ }^{11,12}$ Potential respondents were selected using a cluster sampling methodology with an approximately equal number of surveys sent to each MPO. We received a total of 509 completed surveys, yielding a response rate of $16.2 \%$ (shown in Table 3.) The response rates were more or less consistent across the MPOs, ranging from a low of $16.1 \%$ in the Albany MPO to $16.3 \%$ in the Central Lane and Rogue Valley MPOs. Not all respondents completed all questions to the survey; throughout the report we present the number of respondents (' $n$ ' or the sample size) for each question to provide context.

Table 3: Stratified Sample Scheme

\begin{tabular}{lccc}
\hline Region & Sample Size & Responses & Response Rate \\
\hline Albany MPO & 1,037 & 167 & $16.1 \%$ \\
Central Lane MPO & 1,099 & 179 & $16.3 \%$ \\
Rogue Valley MPO & 1,000 & 163 & $16.3 \%$ \\
\hline Total & $\mathbf{3 , 1 3 6}$ & $\mathbf{5 0 9}$ & $\mathbf{1 6 . 2} \%$
\end{tabular}

Source: Oregon Livability Survey, 2017.

A key concern of researchers who conduct surveys is statistical validity. If one were to assume that the sample was perfectly random and that there was no response bias, then the survey would have a margin of error of $\pm 4.1 \%$ at the $95 \%$ confidence level. ${ }^{13}$ One limitation of the study's methodology is potential non-response bias from the mailed and online survey. The survey results represent higher percentages of females, individuals age 55 or over, and with higher levels of educational attainment than reported by the American Community Survey.

\subsection{FOCUS GROUPS}

To interpret survey results and refine their understanding of livability, the research team conducted six 90-minute focus groups. Two focus group meetings were held in each case study MPO.

The structure and activities of the focus groups explored the results of the Oregon Livability Survey in more detail. The research team held focus group meetings in Albany, Ashland, Medford, and Eugene. Thirty-five people participated in total. The focus group meetings took approximately 90 minutes. The research team recruited focus group participants through the survey and by invitation through local networks.

\footnotetext{
${ }^{11}$ Oregon State Elections Division (2017-01-09). "Voter Registration by County"(PDF). Oregon.gov. Oregon Secretary of State. Retrieved 2017-08-28.

12 Bureau, US Census. "Data." Selected Characteristics of the Citizen, 18 and Older Population. October 28, 2016. Accessed August 28, 2017. https://www.census.gov/data/tables/time-series/demo/voting-and-registration/electorate-profiles-2016.html.

13 The survey uses a cluster sampling methodology that intended to obtain a reliable sample based on "place types." A more detailed discussion of the sampling methods is included in Appendix B.
} 
The individual focus group discussions had a maximum of eight participants; in some locations we had two groups running simultaneously. Each focus group had a facilitator, timekeeper, and one or more note takers. The focus group meetings included facilitated discussion around broad open-ended questions. The focus group methods and results are discussed in more detail in a report titled "The Influence of the Built Environment on Perceptions of Livability in Small Oregon Metropolitan Areas" (Community Service Center, University of Oregon, February 2018). 


\subsection{FINDINGS}

This chapter presents findings from our research. It starts with findings from the household survey, then discusses key findings from a series of focus groups conducted as a part of the research and concludes with the results of the statistical analysis.

\subsection{SURVEY FINDINGS}

This section presents findings from the household survey. The survey methods are described in detail in Section 3 of this report. We intentionally begin with a discussion of respondent characteristics. This provides context for interpreting the survey results as well as understanding the representativeness of the survey. The remainder of the discussion is organized similar to the survey instrument.

\subsubsection{Respondent Characteristics}

This section describes the demographic characteristics of survey respondents. We use American Community Survey data to compare respondent characteristics with population characteristics of Albany MPO, Central Lane MPO, and Rouge Valley MPO. The intent is to document (1) the characteristics of survey respondents, and (2) how the sample compares to the larger population. Table 4 shows the age distribution of residents in the study area MPOs over 18 and of survey respondents. About $40 \%$ of the respondents were 65 years of age or older and $23 \%$ were aged 55 to 64 years old - or $63 \%$ of respondents were age 55 or over. This compares with about $24 \%$ of the MPO population. With respect to younger ages, $16 \%$ of the sample population was aged between 18 and 34 compared to $45 \%$ of the MPO population. While we received a disproportionate number of people aged 55+, we grouped responses by age group into three categories to obtain enough responses per group for statistical analysis. We combined 18-34 (Millenial), 35-54 (GenX), and 55 and older (Boomer).

Table 4: Age Distribution of Survey Respondents Compared to the MPO Population 18 and Over

\begin{tabular}{|c|c|c|c|c|}
\hline \multirow[b]{2}{*}{ Age } & \multicolumn{2}{|c|}{ MPO Population } & \multicolumn{2}{|c|}{ Survey Responses } \\
\hline & Number & Percent & Number & Percent \\
\hline 18 to 19 years & 33,013 & $12.8 \%$ & 8 & $1.5 \%$ \\
\hline 20 to 24 years & 44,736 & $17.3 \%$ & 23 & $4.3 \%$ \\
\hline 25 to 34 years & 38,375 & $14.8 \%$ & 57 & $10.6 \%$ \\
\hline 35 to 44 years & 36,686 & $14.2 \%$ & 53 & $9.8 \%$ \\
\hline 45 to 54 years & 42,513 & $16.4 \%$ & 64 & $11.9 \%$ \\
\hline 55 to 64 years & 37,333 & $14.4 \%$ & 122 & $22.6 \%$ \\
\hline 65 years and over & 25,962 & $10.0 \%$ & 213 & $39.4 \%$ \\
\hline Total & 258,618 & $100.0 \%$ & 540 & $100.0 \%$ \\
\hline
\end{tabular}


Source: Oregon Livability Survey, Q28, 2017. U.S. Census ACS 2011-2015 (5-Year Estimates)

Table 5 shows annual household income as reported by survey respondents and the ACS. The income distribution of the survey sample much more closely mirrors that of the study area MPO populations than for other demographic characteristics.

Table 5: Household Income in 2016, Survey Respondents and MPO

\begin{tabular}{|c|c|c|c|c|}
\hline \multirow[b]{2}{*}{ Age } & \multicolumn{2}{|c|}{ MPO Population } & \multicolumn{2}{|c|}{ Survey Responses } \\
\hline & Number & Percent & Number & Percent \\
\hline Less than $\$ 15,000$ & 28,162 & $17 \%$ & 53 & $10 \%$ \\
\hline$\$ 15,000$ to $\$ 24,999$ & 21,365 & $13 \%$ & 60 & $12 \%$ \\
\hline$\$ 25,000$ to $\$ 34,999$ & 19,049 & $11 \%$ & 58 & $11 \%$ \\
\hline$\$ 35,000$ to $\$ 49,999$ & 32,216 & $19 \%$ & 67 & $13 \%$ \\
\hline$\$ 50,000$ to $\$ 74,999$ & 24,171 & $14 \%$ & 104 & $21 \%$ \\
\hline$\$ 75,000$ to $\$ 149,999$ & 34,216 & $20 \%$ & 115 & $23 \%$ \\
\hline$\$ 150,000$ or more & 8,485 & $5 \%$ & 48 & $10 \%$ \\
\hline Total & 167,664 & $100 \%$ & 505 & $100 \%$ \\
\hline
\end{tabular}

Source: Oregon Livability Survey, Q29, 2017. U.S. Census ACS 2011-2015 (5-Year Estimates), Income in the Past 12 Months.

Note: ACS Data is for households.

Survey respondents identified predominantly as White (85\%) which is consistent with the population in each study area. With respect to gender, $61 \%$ of respondents identified as female, $37 \%$ as male, and $2 \%$ indicated non-binary/preferred not to say. Three-fifths of the respondents were female while ACS data suggests the study areas have a relatively even male-to-female ratio.

Most respondents own their current home (68\%). Two percent of respondents occupy their current home without payment and another $2 \%$ preferred not to say. Respondents homeownership rates are comparable to figures reported by ACS data in the study areas.

Table 6 shows household size of survey respondents compared to ACS data in the study area. On average, respondent households consist of 2.4 persons (2.0 adults 18 years of age and older, and 0.5 children less than 18 years of age) with a majority of respondents (47\%) living in two-person households. The average household size in Oregon is 2.5 persons per household.

Table 6: Household Size of Survey Respondents

\begin{tabular}{|c|c|c|}
\hline Persons per household & Survey Respondents & Oregon Population \\
\hline 1 person & $20 \%$ & $28 \%$ \\
\hline 2 person & $39 \%$ & $34 \%$ \\
\hline 3 Person & $16 \%$ & $16 \%$ \\
\hline 4+ Person & $25 \%$ & $23 \%$ \\
\hline Total & 531 & - \\
\hline Persons per household (Average) & 2.5 & 2.5 \\
\hline Persons per household (Median) & 2.0 & - \\
\hline
\end{tabular}


Source: Oregon Livability Survey, Q34 2017. U.S. Census Bureau, 2016 American Community Survey 1-Year Estimates, Oregon.

With respect to mobility, about half of the respondents changed residence within the last five years and an additional 26\% moved within the last 10 years.

\subsubsection{Survey Findings}

The following sections present key findings from the household survey. The sections are organized around the survey instrument (see Appendix A) and are presented in the following order:

- General Perceptions of Livability

- Influence of the Built Environment on Perceptions of Livability

- Influence of Residence and Neighborhood on Perceptions of Livability

- Influence of Transportation Infrastructure on Perceptions of Livability

This analysis is descriptive in nature and primarily relies on frequency distributions. To test relationships between key characteristics, the research team conducted cross-tabulations and calculated chi-square statistics.

\subsubsection{General Perceptions of Livability}

Perceptions of livability vary from individual to individual. This section therefore discusses the questions getting at general perceptions of livability related to different geographic levels and basic, community factors.

Table 7 shows that most respondents are satisfied with where they live. Residents are most satisfied with their house/home (86\%) followed by their state (82\%). The percentage of respondents who indicated they were somewhat dissatisfied or extremely dissatisfied for any category never exceeded $16 \%$.

Table 7: Respondent Satisfaction with House/Home, Neighborhood, City, County, and State

\begin{tabular}{lcccccc}
\hline Area & $\begin{array}{c}\text { Extremely } \\
\text { Satisfied }\end{array}$ & $\begin{array}{c}\text { Somewhat } \\
\text { Satisfied }\end{array}$ & $\begin{array}{c}\text { Neither } \\
\text { Satisfied or } \\
\text { Dissatisfied }\end{array}$ & $\begin{array}{c}\text { Somewhat } \\
\text { Dissatisfied }\end{array}$ & $\begin{array}{c}\text { Extremely } \\
\text { dissatisfied }\end{array}$ & $\mathbf{n}$ \\
\hline House/Home & $\mathbf{4 8 \%}$ & $38 \%$ & $5 \%$ & $6 \%$ & $3 \%$ & 557 \\
Neighborhood & $36 \%$ & $\mathbf{3 8 \%}$ & $9 \%$ & $13 \%$ & $3 \%$ & 550 \\
\hline City & $25 \%$ & $\mathbf{4 5 \%}$ & $14 \%$ & $13 \%$ & $3 \%$ & 550 \\
County & $24 \%$ & $\mathbf{4 4 \%}$ & $19 \%$ & $11 \%$ & $2 \%$ & 549 \\
\hline State (Oregon) & $\mathbf{4 9 \%}$ & $33 \%$ & $7 \%$ & $7 \%$ & $3 \%$ & 550
\end{tabular}

Source: Oregon Livability Survey, Q1, 2017.

Cross-tabulation of age by satisfaction shows that age (as grouped by generations) significantly influenced respondents' satisfaction for home, neighborhood, city, county, and state. Millennials were less satisfied with each geographic place than Generation X respondents, and Generation X 
respondents less than Baby Boomers. While $90 \%$ of Baby Boomers were somewhat or very satisfied with their homes, this same level of satisfaction was only held by $79 \%$ of Generation $\mathrm{X}$ respondents and $76 \%$ of Millennials (see Figure 2).

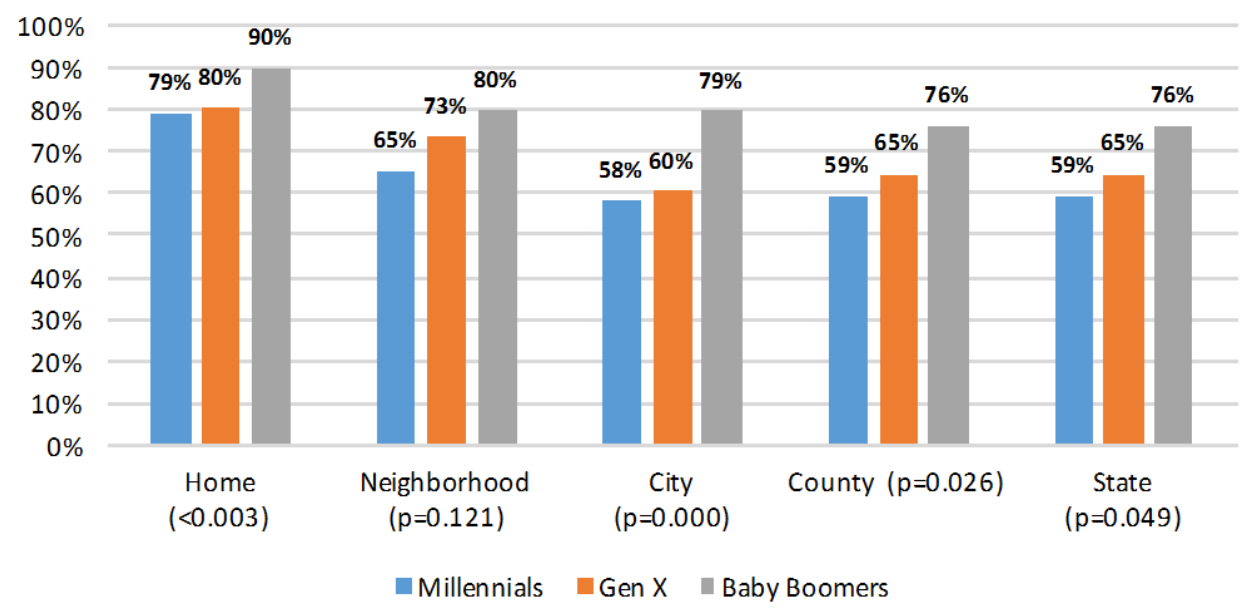

Figure 2: Satisfaction with Residence and Location by Generation Source: Oregon Livability Survey, Q1, 2017.

Note: P-value statistic represents chi-square.

Table 8 shows the importance of factors to respondents in selecting their current home or neighborhood. The most important factors were affordability and crime levels; over $90 \%$ of respondents rated these factors as somewhat or extremely important. Dwelling characteristics (84\%) and proximity to parks and open space (81\%) were also important to respondents.

Table 8: Respondent Rating of Importance of Factors for Selecting Current Home or Neighborhood

\begin{tabular}{|c|c|c|c|c|c|c|}
\hline Factor & $\begin{array}{l}\text { Extremely } \\
\text { Important }\end{array}$ & $\begin{array}{l}\text { Somewhat } \\
\text { Important }\end{array}$ & $\begin{array}{l}\text { Neither Importar } \\
\text { nor Unimportan }\end{array}$ & $\begin{array}{l}\text { Somewhat } \\
\text { Unimportant }\end{array}$ & $\begin{array}{c}\text { Extremely } \\
\text { Unimportant }\end{array}$ & $\mathbf{n}$ \\
\hline Affordability & $72 \%$ & $23 \%$ & $3 \%$ & $1 \%$ & $1 \%$ & 500 \\
\hline Crime Levels & $66 \%$ & $27 \%$ & $5 \%$ & $2 \%$ & $1 \%$ & 499 \\
\hline House Characteristics & $41 \%$ & $43 \%$ & $13 \%$ & $3 \%$ & $1 \%$ & 499 \\
\hline Proximity to Parks/Open Space & $32 \%$ & $49 \%$ & $15 \%$ & $3 \%$ & $1 \%$ & 497 \\
\hline Distance to Retail/Services & $21 \%$ & $54 \%$ & $18 \%$ & $5 \%$ & $1 \%$ & 494 \\
\hline Proximity to Neighbors & $22 \%$ & $49 \%$ & $22 \%$ & $5 \%$ & $3 \%$ & 499 \\
\hline Access to Transportation Options & $32 \%$ & $34 \%$ & $19 \%$ & $11 \%$ & $4 \%$ & 501 \\
\hline Proximity to Work/School & $27 \%$ & $38 \%$ & $23 \%$ & $6 \%$ & $6 \%$ & 496 \\
\hline School Quality & $39 \%$ & $24 \%$ & $23 \%$ & $4 \%$ & $9 \%$ & 481 \\
\hline Neighborhood Characteristics & $18 \%$ & $45 \%$ & $26 \%$ & $6 \%$ & $5 \%$ & 496 \\
\hline Proximity to Family Members & $21 \%$ & $30 \%$ & $29 \%$ & $10 \%$ & $10 \%$ & 497 \\
\hline
\end{tabular}

Source: Oregon Livability Survey, Q2, 2017. CPW ordered factors by highest to lowest using the sum of extremely important and somewhat important. 
The survey asked respondents to describe their ideal livable neighborhood in three words. Respondents list 164 distinct qualities. Table 9 shows the 13 most commonly referenced terms. The three words most frequently listed were: safe, friendly, and clean. The survey asked respondents if these three words would describe their ideal livable city. Sixty-nine percent indicated they would, and $27 \%$ indicated they would differ slightly. Four percent indicated they would be completely different.

Table 9: Describe Your Ideal Livable Neighborhood in Three Words

\begin{tabular}{lcc}
\multicolumn{1}{c}{ Qualities } & Number & Percent \\
\hline Safe & 225 & $\mathbf{1 5 \%}$ \\
\hline Friendly & 153 & $\mathbf{1 0 \%}$ \\
\hline Clean & 136 & $\mathbf{9 \%}$ \\
\hline Quiet & 131 & $\mathbf{9 \%}$ \\
\hline Affordability & 103 & $\mathbf{7 \%}$ \\
\hline Aesthetics & 50 & $3 \%$ \\
\hline Walkable & 46 & $3 \%$ \\
\hline Crime Free & 40 & $3 \%$ \\
\hline Maintained & 37 & $2 \%$ \\
\hline Retail and Services & 37 & $\mathbf{2 \%}$ \\
\hline Accessibility & 34 & $\mathbf{2 \%}$ \\
\hline Green & 28 & $\mathbf{2 \%}$ \\
\hline Spacious & 26 & $\mathbf{2} \%$
\end{tabular}

Source: Oregon Livability Survey, Q3, 2017.

The survey asked respondents about their perceptions of livability of their current residence for various geographies. Table 10 shows that $86 \%$ of respondents indicated "good" or "excellent" when rating the livability of their house/home, $76 \%$ for their neighborhood, $71 \%$ for their city, $70 \%$ for their region, and $82 \%$ for their state.

Table 10: Respondent Perceptions of the Livability of Current Home, Neighborhood, City, Region, and State

\begin{tabular}{lccccc}
\hline Geographic Level & Excellent & Good & Fair & Poor & n \\
\hline House/Home & $\mathbf{4 6 \%}$ & $40 \%$ & $12 \%$ & $2 \%$ & 542 \\
Your Neighborhood & $36 \%$ & $\mathbf{4 0 \%}$ & $21 \%$ & $3 \%$ & 542 \\
Your City & $19 \%$ & $\mathbf{5 2 \%}$ & $23 \%$ & $5 \%$ & 542 \\
Your County & $18 \%$ & $\mathbf{5 2 \%}$ & $26 \%$ & $4 \%$ & 543 \\
State (Oregon) & $\mathbf{4 3 \%}$ & $\mathbf{3 9 \%}$ & $\mathbf{1 4 \%}$ & $\mathbf{4} \%$ & 539
\end{tabular}

Source: Oregon Livability Survey, Q5, 2017.

Cross-tabulation of age by perception of livability shows that age (as grouped by generations) significantly influenced respondent perceptions of livability for home, city, county, and state. Perceptions of neighborhood livability did not have a statistically significant correlation. A lower percentage of Millennials perceived livability of each geographic place than Generation X 
respondents, and Generation X respondents less than Baby Boomers. While $90 \%$ of Baby Boomers consider the livability of their home good or excellent, this same level of satisfaction was held by $80 \%$ of Generation X respondents and $79 \%$ of Millennials (see Figure 3). A similar pattern exists for all geographic levels.

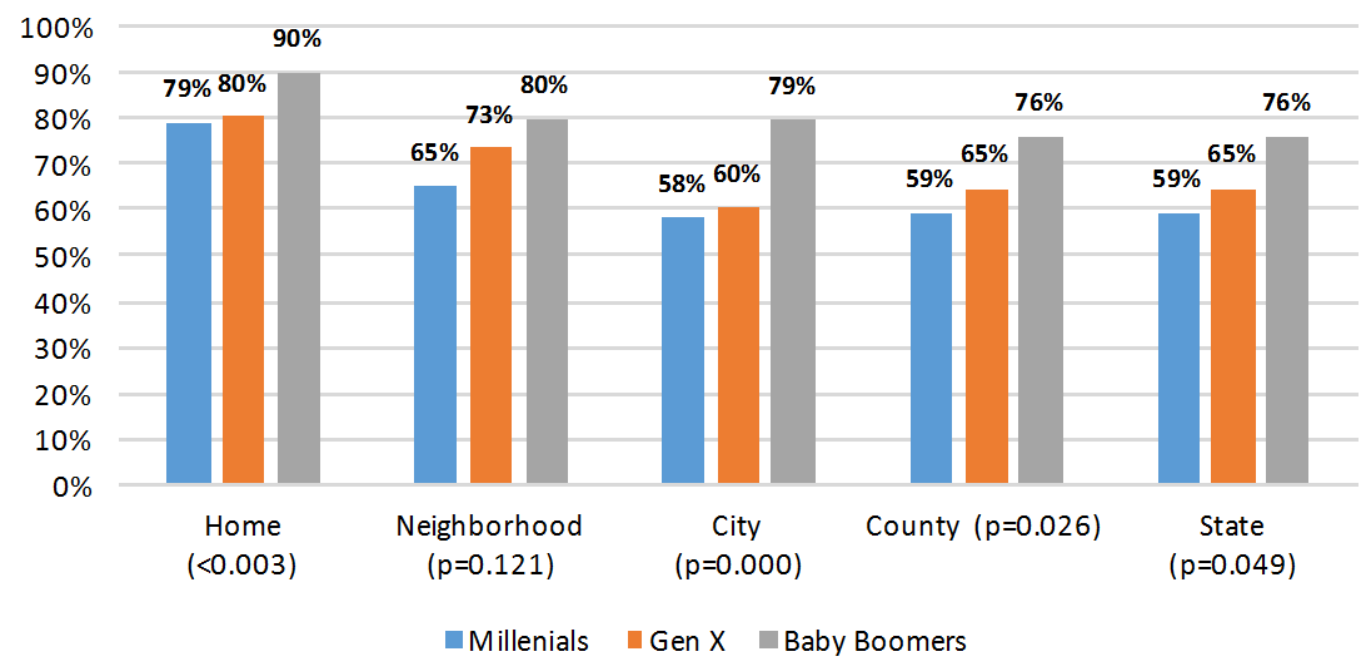

Figure 3: Respondent Perceptions of the Livability of Current Home, Neighborhood, City, Region, and State Source: Oregon Livability Survey, Q5, 2017.

\subsubsection{Influence of the Built Environment on Perceptions of Livability}

This section describes respondents' perceptions of livability as it relates to the built environment, which includes man-made infrastructure such as roads, sidewalks, parking choices, housing choices, and the proximity between varying commercial, residential, and other land uses.

The survey asked respondents to indicate streets and intersections that would create an ideal neighborhood for them. Figure 4 shows that sidewalks (70\%) and trees or greenery (65\%) were the most frequently indicated characteristics of a street or intersection. Crosswalks (49\%), traffic signs (42\%), and dedicated bicycle facilities (31\%) were desired by between one-quarter and one-half of respondents. Less than a quarter of respondents indicated that traffic lights, curb ramps, protected turn lanes, extended curbs and raised sidewalks were desired street or intersection characteristics. 


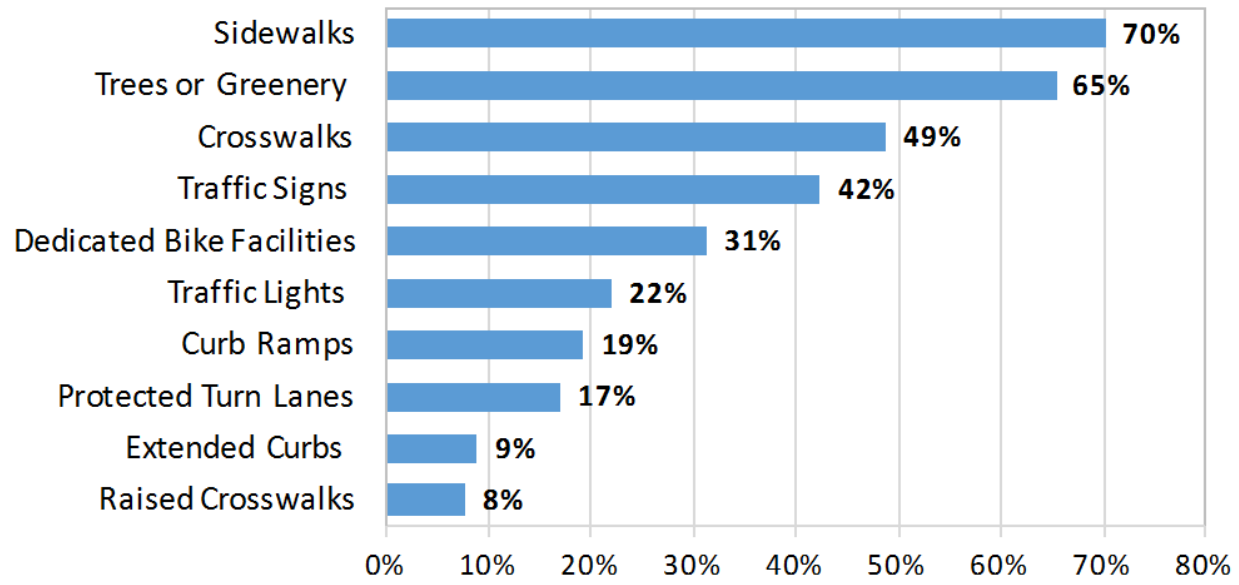

Figure 4: Desired Street or Intersection Characteristics in Respondents’ Ideal Neighborhood Source: Oregon Livability Survey, Q10, 2017.

The survey asked respondents to indicate what level of foot traffic they would consider ideal and the level in the neighborhood of their residence. Responses suggest that neighborhood patterns that produce moderate and intermittent foot traffic are perceived most ideal, which corresponds with the level that respondents report in their neighborhoods (See Figure 5).

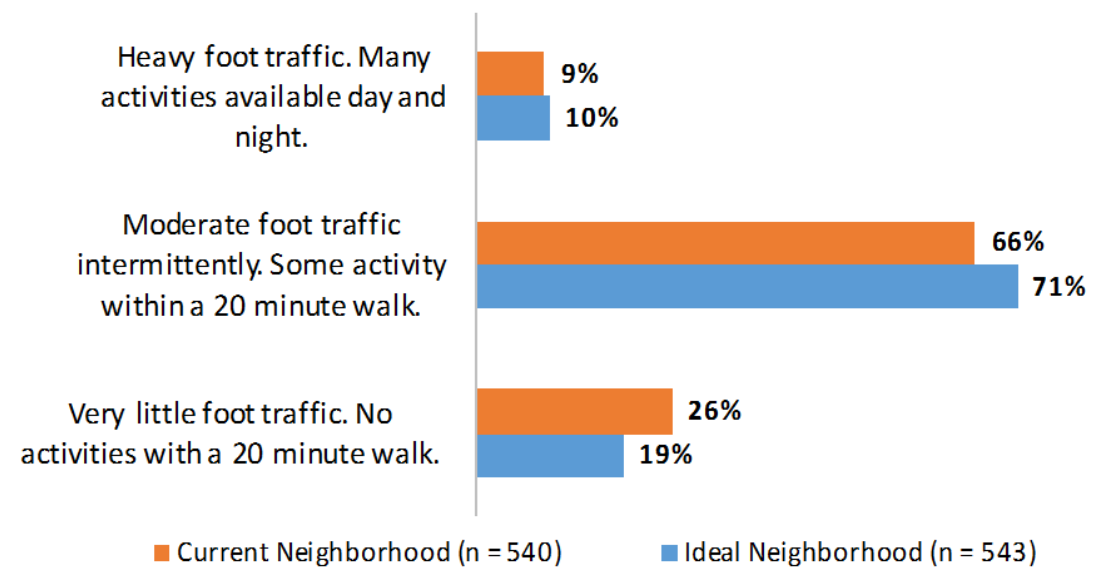

Figure 5: Respondent Perceptions of Level of Foot Traffic: Current Level in their Neighborhood and Ideal Neighborhood

Source: Oregon Livability Survey, Q6 and Q7, 2017.

The survey asked respondents about preferred location of parking in their ideal neighborhood. Figure 6 shows that the two most favored types of parking in respondents' ideal neighborhood are typical off-street parking facilities, personal garages (27\%) and driveways (26\%). The least preferred types of parking are parking lots in front of buildings (4\%), parking lots on the side of buildings (6\%), parking garages (7\%), and parking lots behind buildings (8\%). 


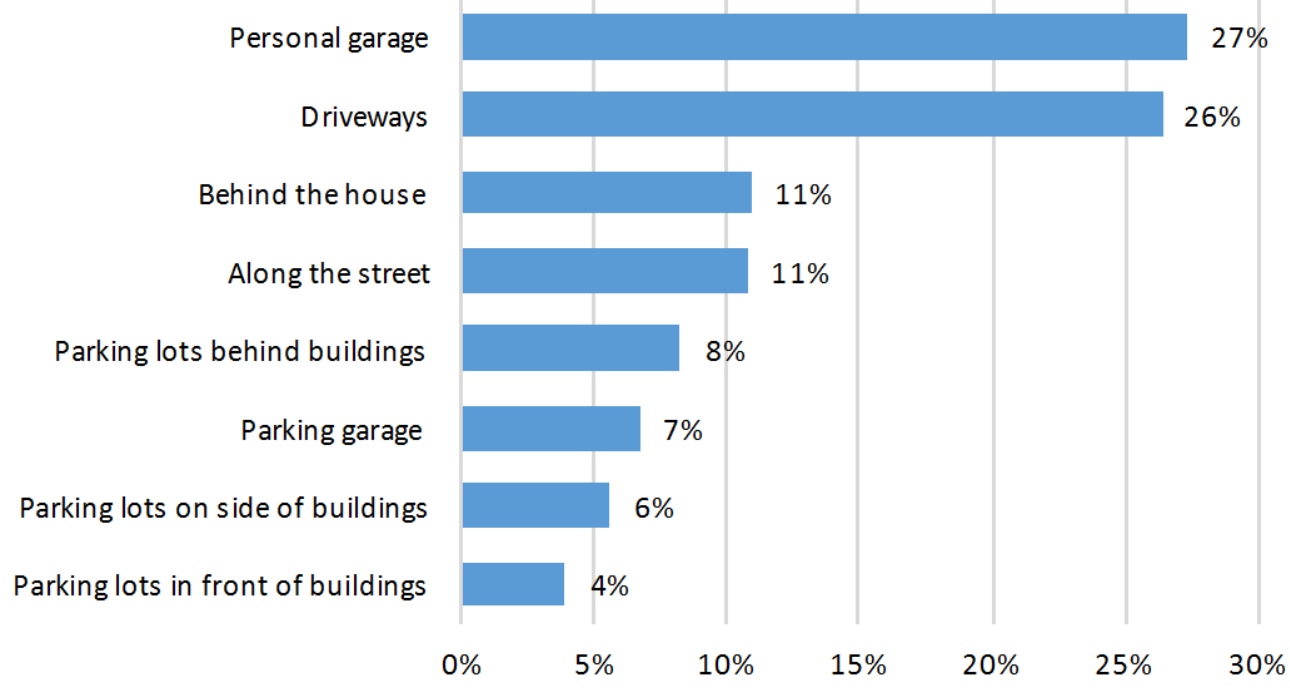

Figure 6: Respondents’ Preferred Location of Parking in an Ideal Neighborhood Source: Oregon Livability Survey, Q8, 2017.

The research team was interested in how important proximity to various amenities within a 20minute walking distance was to respondents. Table 11 shows interesting patterns. Amenities that serve residents, such as parks, grocery stores and other services, were all identified as somewhat important or extremely important by more than half of the respondents. The amenities ranked as most important were parks and open space (79\%), grocery stores (73\%), and public services (65\%). Amenities that are more a function of culture or choice - place of work, schools, and religious or cultural services - all ranked as less important. One interpretation of this result is that the quality or characteristics of these amenities is more important to respondents than proximity to their residences.

Table 11: Importance of Living Within a 20-Minute Walk of Specific Amenities

\begin{tabular}{|c|c|c|c|c|c|c|}
\hline Amenities & $\begin{array}{l}\text { Extremely } \\
\text { Important }\end{array}$ & $\begin{array}{l}\text { Somewhat } \\
\text { Important }\end{array}$ & $\begin{array}{l}\text { Neither Important } \\
\text { nor Unimportant }\end{array}$ & $\begin{array}{l}\text { Somewhat } \\
\text { Unimportant }\end{array}$ & $\begin{array}{l}\text { Extremely } \\
\text { Unimportant }\end{array}$ & $\mathbf{n}$ \\
\hline Parks and Public/Open Space & $42 \%$ & $37 \%$ & $14 \%$ & $4 \%$ & $2 \%$ & 545 \\
\hline Grocery Store & $35 \%$ & $38 \%$ & $17 \%$ & $6 \%$ & $3 \%$ & 548 \\
\hline Public Services & $21 \%$ & $44 \%$ & $24 \%$ & $8 \%$ & $3 \%$ & 548 \\
\hline Shops and Services & $21 \%$ & $43 \%$ & $23 \%$ & $9 \%$ & $4 \%$ & 536 \\
\hline Medical Services & $21 \%$ & $42 \%$ & $27 \%$ & $7 \%$ & $3 \%$ & 547 \\
\hline Transit Station / Bus Stops & $24 \%$ & $32 \%$ & $27 \%$ & $8 \%$ & $8 \%$ & 546 \\
\hline Restaurants and Entertainment & $16 \%$ & $39 \%$ & $29 \%$ & $11 \%$ & $5 \%$ & 546 \\
\hline School or Children's School & $23 \%$ & $27 \%$ & $29 \%$ & $8 \%$ & $13 \%$ & 539 \\
\hline Other & $29 \%$ & $16 \%$ & $33 \%$ & $7 \%$ & $15 \%$ & 55 \\
\hline Work & $15 \%$ & $25 \%$ & $37 \%$ & $10 \%$ & $13 \%$ & 534 \\
\hline Religious or Cultural Services & $9 \%$ & $28 \%$ & $36 \%$ & $14 \%$ & $13 \%$ & 547 \\
\hline
\end{tabular}

Source: Oregon Livability Survey, Q9, 2017. CPW ordered amenities by highest to lowest percentage of aggregated extremely important and somewhat important. 
The survey asked respondents about the importance of proximity to shops and services and whether respondents of different generations had different perspectives. Figure 7 shows that Boomers and Gen-Xers rated proximity to shops and services significantly more important than Millennials. This comparison between these groups resulted in a difference that was statistically significant $(\mathrm{p}=0.000)$.

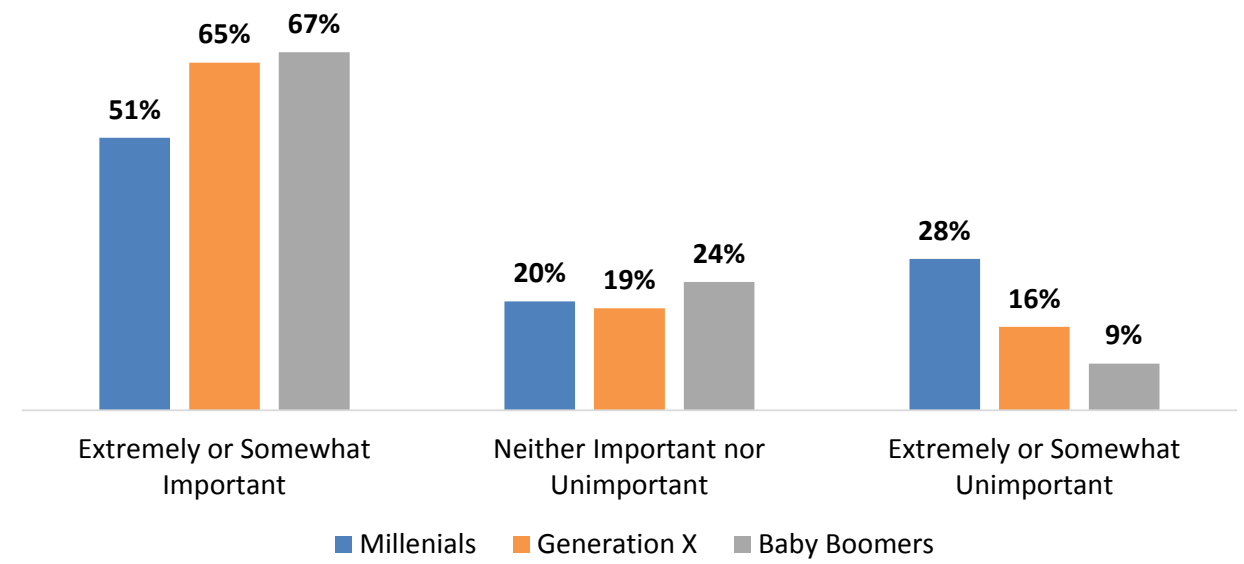

Figure 7: Importance of Living with a 20-Minute Walk to Shops and Services, by Generation Source: Oregon Livability Survey, Q9, 2017.

Planners have promoted mixed-use development as a livability strategy for two or more decades. The survey asked respondents what mixture of land uses they would most prefer in their ideal neighborhood. Figure 8 shows desired mix of land uses in respondents' ideal neighborhood by generation. Forty-seven percent of all respondents prefer residential uses surrounding their house with a mix of uses further away. About $37 \%$ preferred a land use pattern that was a strictly residential neighborhood, and the least most popular pattern was a mixed-use neighborhood. Millennials show a greater preference for a mix of uses in their neighborhood than either GenXers or Boomers. Twenty-four percent of Millennials preferred only residential in their ideal neighborhood compared to $37 \%$ of Gen-Xers and $40 \%$ of Boomers. Notably, very few respondents of any generation prefer office buildings in their ideal neighborhood.

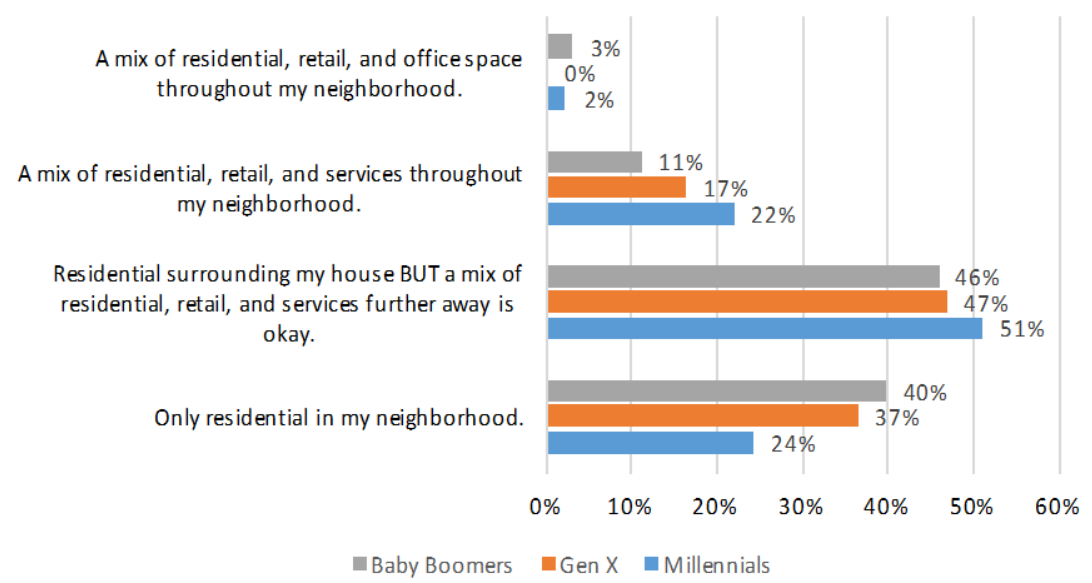

Figure 8: Desired Mix of Land Uses in Respondents' Ideal Neighborhood, by Generation Source: Oregon Livability Survey, Q11, 2017. Note: $p=0.024$ 
Figure 9 shows that $88 \%$ of respondents preferred a neighborhood with detached, single-family housing. The next most preferred housing types were secondary dwelling units (35\%), duplexes (31\%), and townhouses (30\%). Least preferred were manufactured homes (11\%) and temporary housing (3\%).

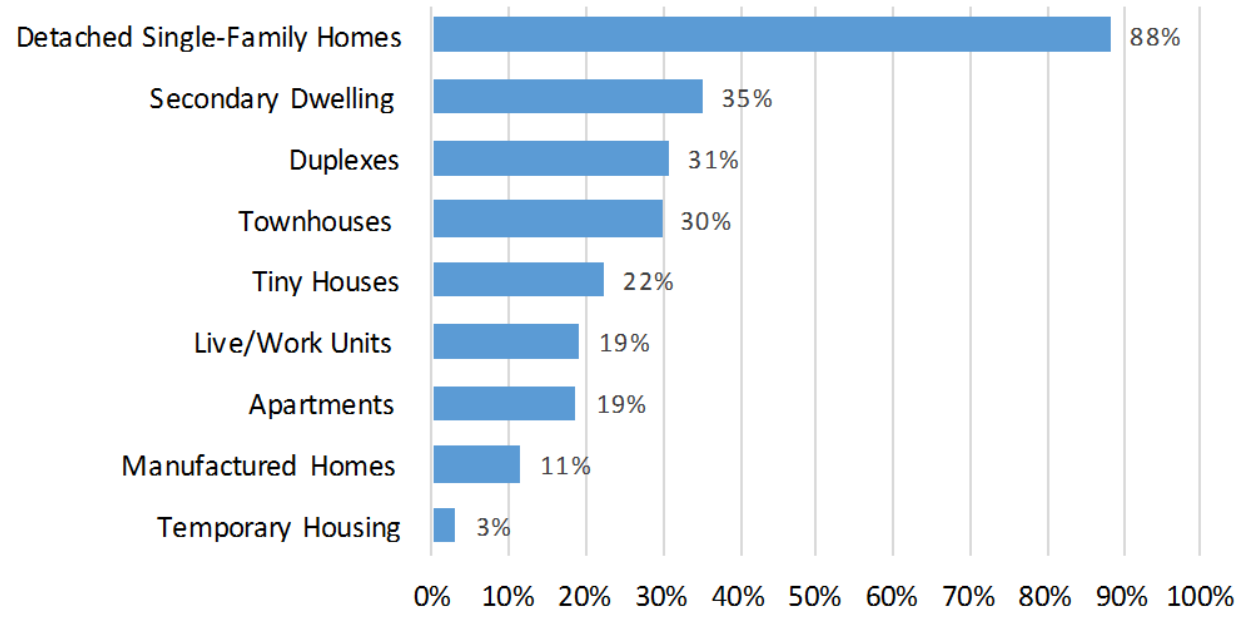

Figure 9: Preferred Housing in Respondents' Ideal Neighborhood

Source: Oregon Livability Survey, Q12, 2017.

The survey asked respondents how important having/seeing a range of different elements were within a 20-minute walk of their ideal home (Table 12). Elements that were somewhat or extremely important to $80 \%$ of respondents or more included presence of quality housing (92\%), presence of sidewalks (91\%), presence of tree-lined streets (87\%), and presence of natural features/biodiversity (83\%). Elements considered neither important nor unimportant were the presence of buildings in a similar style/design, presence of short blocks, presence of street layout on a grid, and the presence of cul-de-sacs. 
Table 12: Importance of Built Environment Elements Within a 20-Minute Walk of Ideal Home

\begin{tabular}{|c|c|c|c|c|c|c|}
\hline Element & $\begin{array}{l}\text { Extremely } \\
\text { Important }\end{array}$ & $\begin{array}{l}\text { Somewhat } \\
\text { Important }\end{array}$ & $\begin{array}{l}\text { Neither Important } \\
\text { nor Unimportant }\end{array}$ & $\begin{array}{c}\text { Somewhat } \\
\text { Unimportant }\end{array}$ & $\begin{array}{c}\text { Extremely } \\
\text { Unimportant }\end{array}$ & $\mathbf{n}$ \\
\hline Presence of Sidewalks & $61 \%$ & $30 \%$ & $6 \%$ & $1 \%$ & $2 \%$ & 496 \\
\hline Presence of Quality Housing & $51 \%$ & $42 \%$ & $5 \%$ & $1 \%$ & $1 \%$ & 493 \\
\hline Presence of Tree-Lined Streets & $47 \%$ & $40 \%$ & $11 \%$ & $2 \%$ & $1 \%$ & 498 \\
\hline Presence of Natural Features/Biodiversity & $47 \%$ & $36 \%$ & $14 \%$ & $2 \%$ & $2 \%$ & 495 \\
\hline Presence of Public Spaces & $31 \%$ & $41 \%$ & $21 \%$ & $4 \%$ & $3 \%$ & 489 \\
\hline Presence of Wide Roads/Streets & $30 \%$ & $46 \%$ & $17 \%$ & $4 \%$ & $3 \%$ & 487 \\
\hline Presence of Buildings Setback at least 10 feet from Street & $24 \%$ & $46 \%$ & $20 \%$ & $5 \%$ & $4 \%$ & 493 \\
\hline Presence of Physical Boundary or Border in Neighborhood & $17 \%$ & $38 \%$ & $34 \%$ & $7 \%$ & $3 \%$ & 494 \\
\hline Presence of Building Diversity in Style/Design & $10 \%$ & $43 \%$ & $34 \%$ & $7 \%$ & $6 \%$ & 493 \\
\hline Presence of Buildings with Similar Heights & $9 \%$ & $36 \%$ & $37 \%$ & $10 \%$ & $8 \%$ & 494 \\
\hline Presence of Street Layout on a Grid & $7 \%$ & $28 \%$ & $48 \%$ & $11 \%$ & $6 \%$ & 490 \\
\hline Presence of Short Blocks & $7 \%$ & $29 \%$ & $50 \%$ & $10 \%$ & $4 \%$ & 494 \\
\hline Presence of Cul-de-sac & $6 \%$ & $20 \%$ & $49 \%$ & $13 \%$ & $11 \%$ & 495 \\
\hline Presence of Buildings in a Similar Style/Design & $3 \%$ & $25 \%$ & $46 \%$ & $17 \%$ & $10 \%$ & 493 \\
\hline
\end{tabular}

Source: Oregon Livability Survey, Q13, 2017. 
When asked whether the elements listed in Table 12 were important to be visually interesting in their neighborhoods, $80 \%$ of respondents indicated that it was important they should be visually interesting (see Figure 10). Only 3\% said visually interesting elements were unimportant.

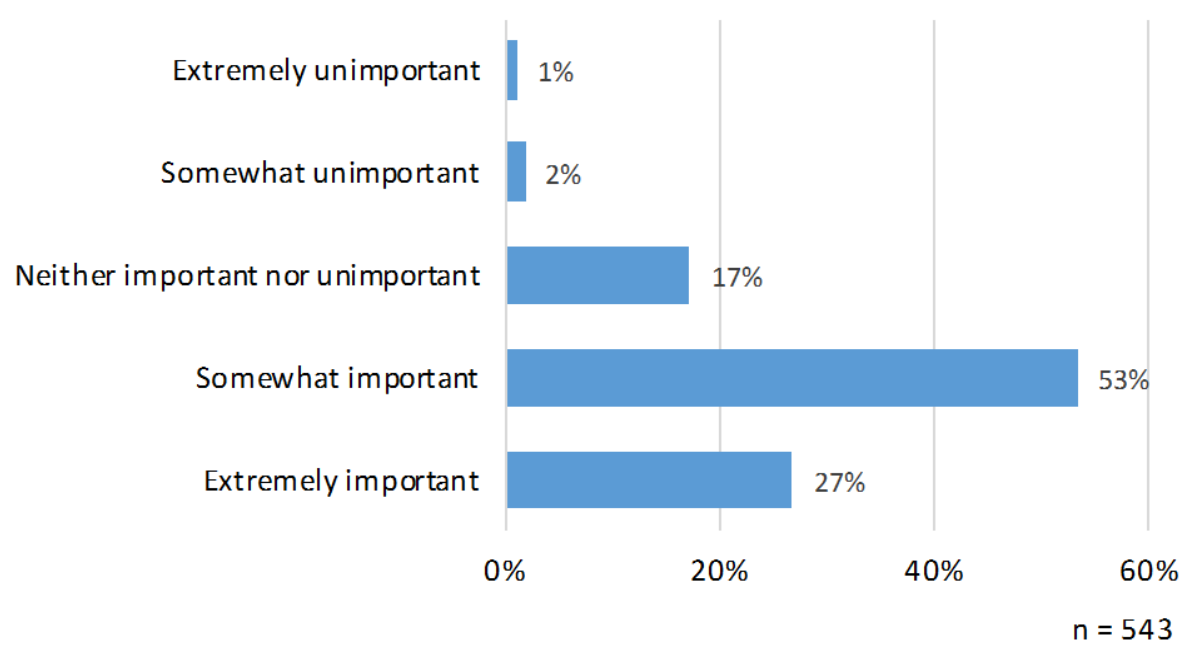

Figure 10: Respondent Ratings of the Importance that Neighborhood Elements are Visually Interesting Source: Oregon Livability Survey, Q14, 2017.

\subsubsection{Influence of Residence and Neighborhood on Perceptions of Livability}

The survey asked a series of questions about how elements of respondents' dwellings and neighborhoods affected their perception of livability. The size and privacy of yards, what type of housing is preferred, and whether the density of a residential neighborhood affects the relationships between residences and neighborhoods were core attributes.

We asked respondents two questions related to outdoor space: What type of outdoor space would you ideally have and what do you currently have? Figure 11 shows that $40 \%$ percent of respondents said they have a medium-sized private yard and a comparable percentage indicated that was their ideal yard size. Respondents show a strong preference for a medium-sized yard or larger (80\%). Nearly $40 \%$ indicated that they would ideally have a large private yard or acreage, while only $17 \%$ reported having that type of outdoor space. 


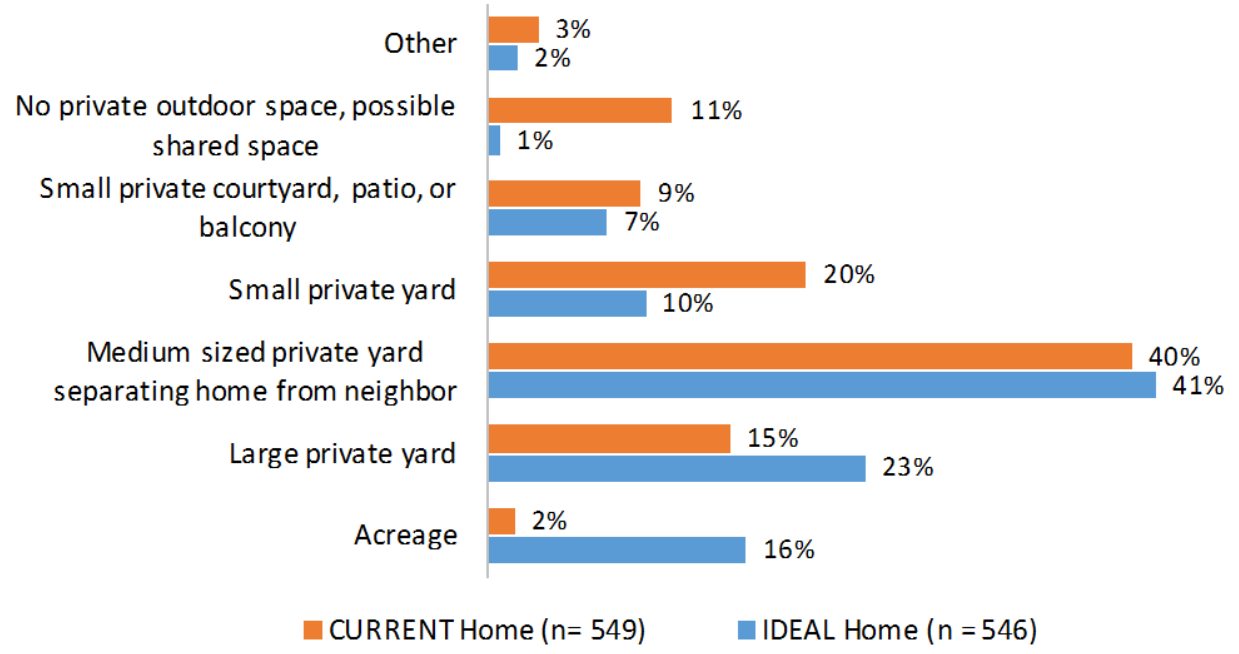

Figure 11: Respondent Description of their Current and Ideal Outdoor Space Source: Oregon Livability Survey, Q15 and Q16, 2017.

We asked respondents to indicate what housing type they currently live in and what they would prefer. Figure 12 shows that a large majority (nearly 90\%) indicated their ideal housing would be a single-family, detached home. About $75 \%$ of the respondents reported they currently live in a detached, single-family home.

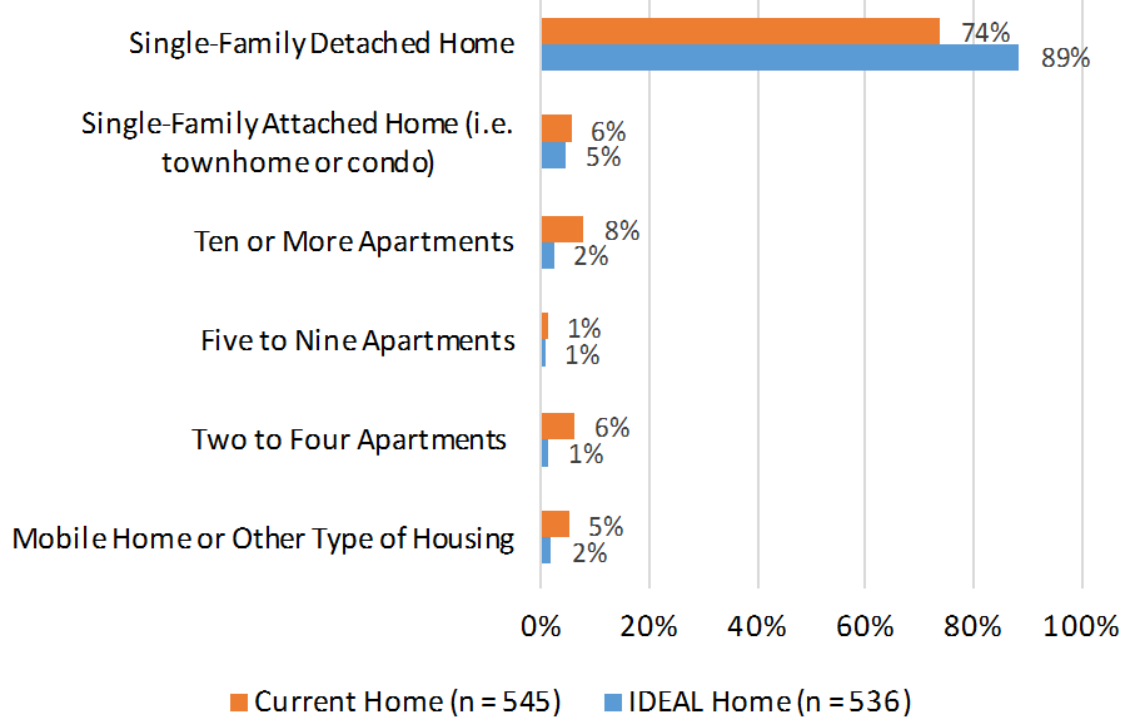

Figure 12: Respondents' Current and Ideal Housing Type Source: Oregon Livability Survey, Q17 and Q18, 2017.

A key topic of interest for this research is the relationship between housing density and perceptions of livability. To better understand respondent perceptions, the survey asked respondents to indicate how dense they think their current neighborhood is and whether they felt their neighborhood was too dense. 
Table 13 compares respondents' perceptions of the density of their neighborhood with the actual density. As a general observation, most respondents did not accurately indicate the actual density of the neighborhood they live in. In fact, 106 of the 378 observations (28\%) indicated the correct density range. For those who did not indicate the correct density range, more respondents (53\%) indicated perceived densities that were higher than the actual density. Nineteen percent of respondents indicated perceived densities that were lower than the actual density in their neighborhood. People in higher density neighborhoods were more accurate than medium or low density neighborhoods.

Table 13: Perceived Neighborhood Density Compared to Actual Neighborhood Density

\begin{tabular}{|c|c|c|c|c|c|c|}
\hline \multirow[b]{2}{*}{ Perceived Density } & \multicolumn{5}{|c|}{ Actual Density } & \multirow[b]{2}{*}{$\begin{array}{c}\text { Number of } \\
\text { Respondents }\end{array}$} \\
\hline & $\begin{array}{c}\text { Rural }(>=0 \\
\text { and }<1 \\
\text { du/ac) }\end{array}$ & $\begin{array}{l}\text { Low (>=1 } \\
\text { and }<3 \\
\text { du/ac) }\end{array}$ & $\begin{array}{c}\text { Medium (>=3 } \\
\text { and }<6 \\
\text { du/ac) }\end{array}$ & $\begin{array}{l}\text { Medium-High } \\
\quad(>=6 \text { and } \\
<12 \text { du/ac) }\end{array}$ & $\begin{array}{l}\text { High }(>=12 \\
\text { du/ac) }\end{array}$ & \\
\hline Rural $(>=0$ and $<1$ du/ac) & $14 \%$ & $4 \%$ & $2 \%$ & $3 \%$ & $12 \%$ & 17 \\
\hline Low $(>=1$ and $<3$ du/ac) & $40 \%$ & $28 \%$ & $21 \%$ & $17 \%$ & $0 \%$ & 91 \\
\hline Medium $(>=3$ and $<6$ du/ac) & $26 \%$ & $43 \%$ & $33 \%$ & $32 \%$ & $0 \%$ & 129 \\
\hline Medium-High ( $>=6$ and $<12$ du/ac) & $12 \%$ & $19 \%$ & $28 \%$ & $19 \%$ & $29 \%$ & 83 \\
\hline High $(>=12 \mathrm{du} / \mathrm{ac})$ & $7 \%$ & $7 \%$ & $16 \%$ & $29 \%$ & $59 \%$ & 59 \\
\hline Total & $100 \%$ & $100 \%$ & $100 \%$ & $100 \%$ & $100 \%$ & \\
\hline Number of Respondents & 42 & 134 & 127 & 59 & 17 & 379 \\
\hline
\end{tabular}

Source: Oregon Livability Survey, Q21, 2017.

When asked whether they thought their neighborhood was too dense, most respondents (73\%) however, did not think their neighborhood was too dense, while 21\% thought their neighborhood is too dense for their liking. Six percent reported they didn't know. Of the respondents who indicated that their neighborhoods were too dense (21\%), about half (55\%) thought their neighborhoods had six or more dwelling units per acre.

Finally, we asked respondents to indicate how dense they thought their neighborhood was compared to the rest of their city. Seventy percent of respondents indicated their neighborhood is medium/moderately dense as compared to the rest of their city; $23 \%$ say their neighborhood is low/not dense compared to the rest of their city; and 7\% say their neighborhood is high/very dense compared to the rest of their city.

\subsubsection{Influence of Transportation Infrastructure on Perceptions of Livability}

This section explores the relationship between transportation options available, choices made, and options desired.

Figure 13 shows that most respondents want a variety of transportation options in their neighborhood. The most frequently selected transportation options were auto/vehicular options (86\%), pedestrian options (80\%), and bicycle options (75\%). 


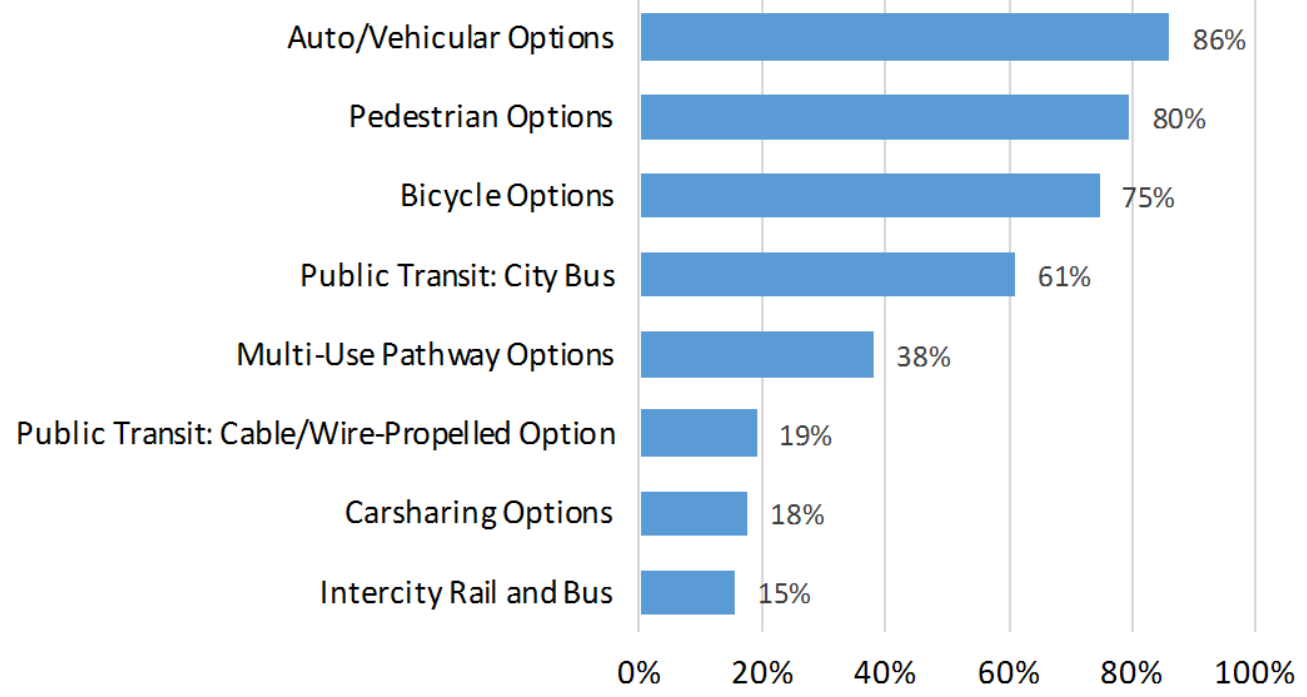

Figure 13: Transportation Options Respondents Want in their Ideal Neighborhood Source: Oregon Livability Survey, Q22, 2017.

The survey asked respondents to indicate what transportation mode they most frequently used to get to various destinations (Table 14). More than 50\% of respondents indicated automobile/carpool for all of the destinations, with more than $90 \%$ reporting using automobile/carpool for shopping. Notably, higher percentages of respondents reported walking to get their children to school (17\%) and to get to parks and open areas (39\%).

Table 14: Respondent Primary Mode Choice for Various Destinations

\begin{tabular}{|c|c|c|c|c|c|}
\hline Question & $\begin{array}{c}\text { Automobile } \\
\text { or Carpool }\end{array}$ & Bicycle & Walk & $\begin{array}{c}\text { Bus/Public } \\
\text { Transit }\end{array}$ & $\mathbf{n}$ \\
\hline How do you get to shopping centers? & $91 \%$ & $3 \%$ & $4 \%$ & $2 \%$ & 537 \\
\hline How do you get to the grocery store? & $90 \%$ & $3 \%$ & $5 \%$ & $2 \%$ & 541 \\
\hline How do you get to work? & $85 \%$ & $5 \%$ & $7 \%$ & $3 \%$ & 356 \\
\hline How do you get your children to school? & $68 \%$ & $5 \%$ & $17 \%$ & $10 \%$ & 184 \\
\hline How do you get to parks and open areas? & $51 \%$ & $8 \%$ & $39 \%$ & $1 \%$ & 525 \\
\hline
\end{tabular}

Source: Oregon Livability Survey, Q23, 2017.

While most respondents reported using automobiles as their primary mode of transportation, it is not the preferred mode for many respondents. When asked about their most preferred transportation mode, $52 \%$ of respondents preferred the auto/vehicular option, while 32\% preferred to walk and 16\% preferred cycling.

Figure 14 shows that $64 \%$ of respondents agree or strongly agree that their neighborhood accommodates all of the transportation options they would want, and $19 \%$ disagree or strongly disagree that their neighborhood accommodates all of the transportation options they want. 
Cross-tabulation analysis showed no statistical differences in responses by age of respondents grouped by generation.

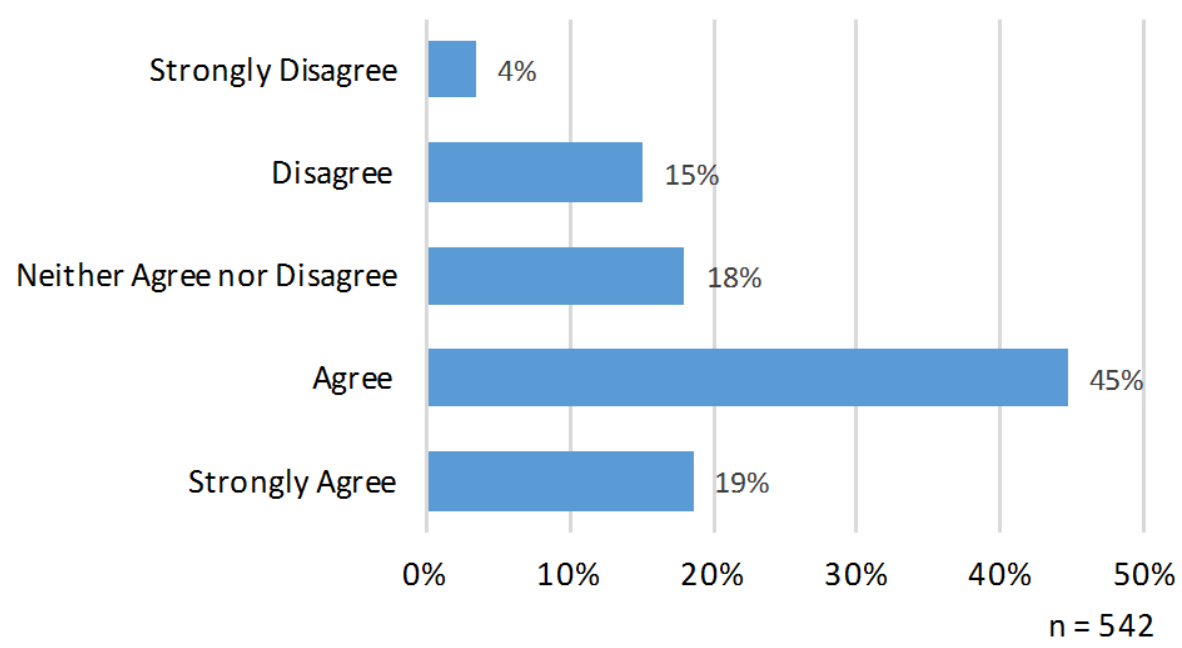

Figure 14: Respondent Perceptions Whether Their Neighborhood Accommodates all the Transportation Options They Want

Source: Oregon Livability Survey, Q25, 2017.

While most respondents agreed that their neighborhood accommodates all of the transportation options they would want to take, including walking and biking, half of respondents (51\%) want their neighborhoods to be more bicycle/pedestrian friendly (see Figure 15).

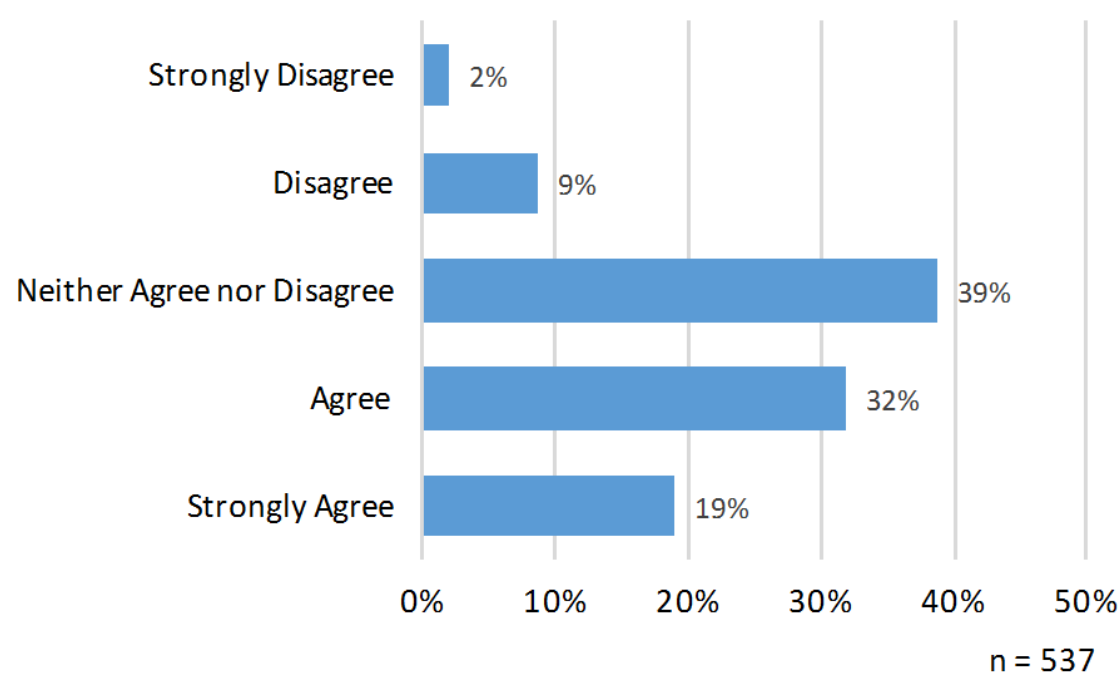

Figure 15: Respondent Agreement with the Statement: "I want my neighborhood to be more bicycle/pedestrianfriendly"

Source: Oregon Livability Survey, Q26, 2017. 


\subsubsection{Key Survey Findings}

Key findings from the Oregon Livability Survey follow:

- Respondents indicated being most satisfied with their home (86\%), followed by their state (82\%), neighborhood (74\%), city (70\%), and county (68\%). The ordering of these geographies based on satisfaction coincides with respondent ordering of geographies based on perceptions of livability. In addition, age influences perception of satisfaction, where older demographics tend to be more content with their current surroundings.

- Neighborhood factors such as housing affordability (72\%) and crime levels (66\%) were rated as slightly more important than factors such as house characteristics and distance to parks and retail services when selecting a home/neighborhood.

- Traditional/basic streetscape elements such as sidewalks, trees, crosswalks, traffic signals, and dedicated bike lines are more desired than modified elements such as curb ramps, protected turn lanes, extended curbs, and raised crosswalks.

- It is important to respondents to live within a 20-minute walk to parks, grocery stores, services and shops, transit stops, and restaurants. Living within a 20-minute walk of schools, work, and religious or cultural services was less important to survey respondents. Amenities that are more a function of culture or choice - place of work, schools, and religious or cultural services - all ranked less important. One interpretation of this result is that the quality or characteristics of these amenities is more important to respondents than proximity to their residences.

- Millennials show a greater preference for a mix of uses in their neighborhood than either Gen-Xers or Boomers. Twenty-four percent of Millennials prefer only residential in their ideal neighborhood compared to $37 \%$ of Gen-Xers and $40 \%$ of Boomers. Notably, very few respondents of any generation prefer office buildings in their ideal neighborhood.

- Respondents preferred a neighborhood with detached, single-family housing (88\%). The next most preferred housing types were secondary dwelling units (35\%), duplexes (31\%), and townhouses (30\%). Least preferred were manufactured homes (11\%) and temporary housing (3\%).

- Forty percent of respondents said they have a medium-sized private yard and a comparable percentage indicated that was their ideal home. Respondents do tend to idealize a medium-sized yard or larger (80\%). Nearly $40 \%$ indicated that they would ideally have a large private yard or acreage, while only $17 \%$ reported having that type of outdoor space.

- Most respondents did not accurately indicate the actual density of the neighborhood they live in. In fact, $28 \%$ indicated the correct density range. For those that did not indicate the correct density range, more respondents (53\%) indicated perceived densities that were 
higher than the actual density. Nineteen percent of respondents indicated perceived densities that were lower than the actual density in their neighborhood.

- Most respondents want a variety of transportation options in their neighborhood. The most frequently selected transportation options were auto/vehicular options (86\%), pedestrian options (80\%), and bicycle options (75\%).

\subsection{REGRESSION ANALYSIS FINDINGS}

To examine the determinants of perceptions of neighborhood livability among respondents, we examined individual characteristics, neighborhood/parcel characteristics, and perception responses. Our dependent variable was: "In your opinion, how livable is your neighborhood," in which respondents rated their neighborhood excellent, good, fair or poor (question 5 on the survey instrument). We recoded the variables to a binary classification in which excellent and good $=1$ and fair or poor $=0$.

Using neighborhood satisfaction research as a framework, we considered several individual, neighborhood/parcel and perception variables which are based on survey responses, Census data, and GIS analysis of individual parcels.

To examine characteristics of individuals, we included categorical variables to represent Millennial, Baby Boomer and Generation X. We omitted Baby Boomers in regression models. We included household income, gender, and college education. We also considered housing type, years in residence, household size, and travel mode to work.

To examine characteristics of the neighborhood, we examined tract-level data representing median household income and percent owner. We examined the household density relying on TAZ data. We also computed parcel-level characteristics including average lot size in the TAZ, distance to nearest retail establishment, parks, and transit stops.

We included several neighborhood perception variables from the survey, including desiring more neighborhood walkability (Q26), neighborhood accommodating transportation options (Q25), neighborhood density (Q19), and factor scores to represent neighborhood choice variables (Q2). To construct these variables, we relied on factor analysis to group the factors used to select the respondents' current home/neighborhood. Based on factor analysis, we computed factor scores of neighborhoods' accessibility, characteristics of the home, and affordability.

\subsubsection{Descriptive Analysis}

Descriptive statistics are summarized in Table 15. The number of respondents varies because of incomplete survey responses or lack of parcel data. 
Table 15 shows averages, ranges and standard deviation for the entire sample and for both categories of the dependent variable. Consistent with our research method, variables are grouped into three categories: (1) individual; (2) neighborhood; and (3) perceptions. 
Table 15: Descriptive Statistics of All Variables

\begin{tabular}{|c|c|c|c|c|c|c|c|c|}
\hline \multirow[b]{2}{*}{ Variable } & \multicolumn{4}{|c|}{ Pooled } & \multicolumn{2}{|c|}{ Livability= Fair/Poor } & \multicolumn{2}{|c|}{ Livability= Good/Excellent } \\
\hline & $\mathbf{N}$ & Min/Max & Mean & St. Dev. & Mean & St. Dev. & Mean & St. Dev. \\
\hline $\begin{array}{l}\text { Livability level of Neighborhood } \\
\text { ( } 0=\text { Fair or Poor; } 1=\text { Excellent or }\end{array}$ & 540 & $0 / 1$ & 0.76 & 0.43 & 0.00 & & 1.00 & \\
\hline \multicolumn{9}{|c|}{ Individual Characteristics } \\
\hline Millenial & 538 & $0 / 1$ & 0.16 & 0.37 & 0.24 & 0.43 & 0.14 & 0.35 \\
\hline Generation X & 538 & $0 / 1$ & 0.22 & 0.41 & 0.24 & 0.43 & 0.21 & 0.41 \\
\hline Baby Boomers (Age) & 538 & $0 / 1$ & 0.62 & 0.49 & 0.52 & 0.50 & 0.65 & 0.48 \\
\hline $\begin{array}{l}\text { Household Income Above State } \\
\text { Median }\end{array}$ & 504 & $0 / 1$ & 0.53 & 0.50 & 0.36 & 0.48 & 0.59 & 0.49 \\
\hline Gender (0=Male; $1=$ Female) & 507 & $0 / 1$ & 0.63 & 0.48 & 0.68 & 0.47 & 0.61 & 0.49 \\
\hline College Educated (1=Yes) & 533 & $0 / 1$ & 0.46 & 0.50 & 0.40 & 0.49 & 0.48 & 0.50 \\
\hline $\begin{array}{l}\text { Housing Type }(0=\text { Other; } \\
1=\text { Single Family Detached }\end{array}$ & 543 & $0 / 1$ & 0.74 & 0.44 & 0.63 & 0.49 & 0.78 & 0.42 \\
\hline Years in Current Residence & 493 & $0 / 63$ & 11.95 & 11.53 & 10.44 & 11.49 & 12.52 & 11.60 \\
\hline Household Size & 553 & $0 / 20$ & 2.25 & 1.52 & 2.45 & 1.63 & 2.25 & 1.48 \\
\hline $\begin{array}{l}\text { Travel mode to work } \\
(0=\text { alternative mode; } \\
1=\text { automobile })\end{array}$ & 354 & $0 / 1$ & 0.85 & 0.36 & 0.87 & 0.34 & 0.84 & 0.37 \\
\hline \multicolumn{9}{|c|}{ Neighborhood/Parcel Characteristics } \\
\hline $\begin{array}{l}\text { Median Household Income } \\
2015 \text { (\$) (tract) }\end{array}$ & 384 & $9103 / 91875$ & $\$ 48,815$ & $\$ 18,845$ & $\$ 41,081$ & $\$ 17,276$ & 51,302 & 18,476 \\
\hline Percent Owner (tract) & 384 & $0.1 / 0.95$ & 0.58 & 0.23 & 0.50 & 0.24 & 0.61 & 0.22 \\
\hline $\begin{array}{l}\text { Household Density (units/acre) } \\
\text { (TAZ) }\end{array}$ & 368 & $0 / 33.67$ & 3.80 & 3.48 & 5.19 & 5.25 & 3.34 & 2.49 \\
\hline $\begin{array}{l}\text { Average Parcel Size in Acres } \\
\text { (parcel) }\end{array}$ & 384 & $0 / 1.28$ & 0.22 & 0.15 & 0.19 & 0.10 & 0.23 & 0.15 \\
\hline $\begin{array}{l}\text { Distance to Retail in Miles } \\
\text { (parcel) }\end{array}$ & 323 & $0 / 1.66$ & 0.44 & 0.29 & 0.38 & 0.20 & 0.47 & 0.32 \\
\hline $\begin{array}{l}\text { Distance to Park in Miles } \\
\text { (parcel) }\end{array}$ & 323 & $0.04 / 6.73$ & 1.54 & 1.53 & 1.29 & 1.29 & 1.67 & 1.62 \\
\hline $\begin{array}{l}\text { Distance to Transit Stop in } \\
\text { Miles (parcel) }\end{array}$ & 322 & $0.1 / 3.51$ & 0.47 & 0.59 & 0.39 & 0.47 & 0.51 & 0.63 \\
\hline Albany MPO & 573 & $0 / 1.00$ & 0.32 & 0.47 & 0.33 & 0.47 & 0.33 & 0.47 \\
\hline Rogue Valley MPO & 573 & $0 / 1.00$ & 0.31 & 0.46 & 0.28 & 0.45 & 0.32 & 0.47 \\
\hline Lane MPO & 573 & $0 / 1.00$ & 0.34 & 0.47 & 0.36 & 0.48 & 0.33 & 0.47 \\
\hline \multicolumn{9}{|c|}{ Individual Perceptions } \\
\hline $\begin{array}{l}\text { Want a more walkable } \\
\text { neighobhrood }\end{array}$ & 544 & $0 / 1.00$ & 0.51 & 0.50 & 0.57 & 0.50 & 0.50 & 0.50 \\
\hline $\begin{array}{l}\text { Neighborhood supports all } \\
\text { transportation choices desired }\end{array}$ & 540 & $0 / 1.00$ & 0.63 & 0.48 & 0.57 & 0.50 & 0.65 & 0.48 \\
\hline Neighborhood is too Dense & 540 & $0 / 1$ & 0.21 & 0.41 & 0.46 & 0.50 & 0.13 & 0.34 \\
\hline $\begin{array}{l}\text { Housing Affordability Important } \\
\text { in Housing Choice (Factor } \\
\text { Score) }\end{array}$ & 508 & $-4.78 / 2.82$ & -0.09 & 1.02 & 0.13 & 1.03 & -0.16 & 1.00 \\
\hline $\begin{array}{l}\text { Housing Characteristics } \\
\text { Important in Housing Choice } \\
\text { (Factor Score) }\end{array}$ & 508 & $-4.12 / 1.90$ & 0.09 & 0.98 & -0.12 & 0.94 & 0.16 & 0.97 \\
\hline $\begin{array}{l}\text { Neighborhood Accessibility } \\
\text { Important in Housing Choice } \\
\text { (Factor Score) }\end{array}$ & 508 & $-4.70 / 2.23$ & -0.03 & 1.03 & -0.23 & 1.12 & 0.04 & 0.97 \\
\hline
\end{tabular}




\subsubsection{Regression Findings}

Table 16 shows regression results including individual, neighborhood and perception variables. We consider each group individually (Model 1-3), and the combinations of groups (Model 4-6), in addition to all variables (Model 7). The dependent variable was computed from question 5 (In your opinion, how livable is your neighborhood," in which respondents rated their neighborhood excellent, good, fair or poor (question 5 on the survey instrument). We recoded the variables to a binary classification in which excellent and good $=1$ and fair or poor $=0$.

Model 1 considers only characteristics of the individual respondent and controls for the MPO. In this model, the explanatory power is relatively weak. The only statistically significant variables (at the $90 \%$ confidence level) are household income and housing type. Higher-income respondents and respondents in single-family, detached homes see their neighborhoods as more livable, all else equal. The direction of variables is also interesting. Millennial groups see their neighborhoods as more livable than Boomers (the omitted category) while Generation X see neighborhoods as less livable. Female, college education, and years in residence also show a positive influence on perception of livability but are not statistically significant. Both Rogue and Lane have a negative influence on livability (relative to Albany) but neither are significant. Model 2 only considers characteristics of the neighborhood. The explanatory power is slightly higher than only considering individual characteristics. Median household income has a positive and statistically significant impact on perception of livability, while percentage homeowners and housing density have a statistically significant and negative impact on perception of livability. Several variables are not statistically significant and the signs are expected, including average parcel size (positive), distance to transit stops (negative meaning being closer has a positive impact). Distance to retail and distance to parks show counterintuitive signs but are not statistically significant. Like Model 1, both Rogue and Lane have a negative influence on livability (relative to Albany) but neither are significant.

Model 3 only considers perception variables. The explanatory power is stronger than both individual and neighborhood characteristics alone. Two variables are statistically significant and negative: neighborhood is too dense and importance of housing affordability in housing choice. On the other hand, neighborhood accessibility as important in housing choice has a positive but statistically significant impact on livability. This shows that there is a tradeoff between affordability and accessibility. Respondents who want a more walkable neighborhood than they have perceive livability more negatively (but this is not statistically significant). Respondents who think their neighborhood has all the transportation choices they desire see the neighborhood more favorably but this is not statistically significant. Both Rogue and Lane have a negative influence on livability (relative to Albany) but neither are significant.

Models 4 through 6 show combinations of variable groups. In this description, we focus on interesting results that vary from Models 1 through 3. All of these models have greater explanatory power than groups of each variable alone, but that is to be expected. Model 6, which shows neighborhood and perception variables, has the strongest explanatory power. In Model 4, only travel mode to work has a statistically significant effect on perception of livability.

Respondents who drive to work perceive their neighborhoods as less livable. Model 5 shows three variables that are statistically significant. In this model, Lane MPO has a negative impact on livability as well as a perception that the neighborhood is too dense. Neighborhood 
accessibility as a factor in housing choice has a positive influence on the perception of livability. Model 6 shows several statistically significant variables. The following variables have a positive and statistically significant impact on livability: median household income, distance to park (being further from parks), and neighborhood supporting all transportation choices. The following variables have a negative and statistically significant impact: percentage of homeowners, household density, Rogue Valley MPO, Lane MPO, perception the neighborhood is too dense, and importance of housing affordability in housing choice.

Finally, Model 7 includes all variables. While the explanatory power improves in this model, statistical significance changes for several variables. The following variables have a positive and statistically significant impact: years in residence, further from retail, further from parks, and perception that the neighborhood includes all transportation choices. The following variables have a negative and statistically significant impact: driving to work, Rogue Valley MPO, Lane MPO, perception that the neighborhood is too dense, housing affordability is important in housing choice, and further from transit. 
Table 16: Regression Model Results

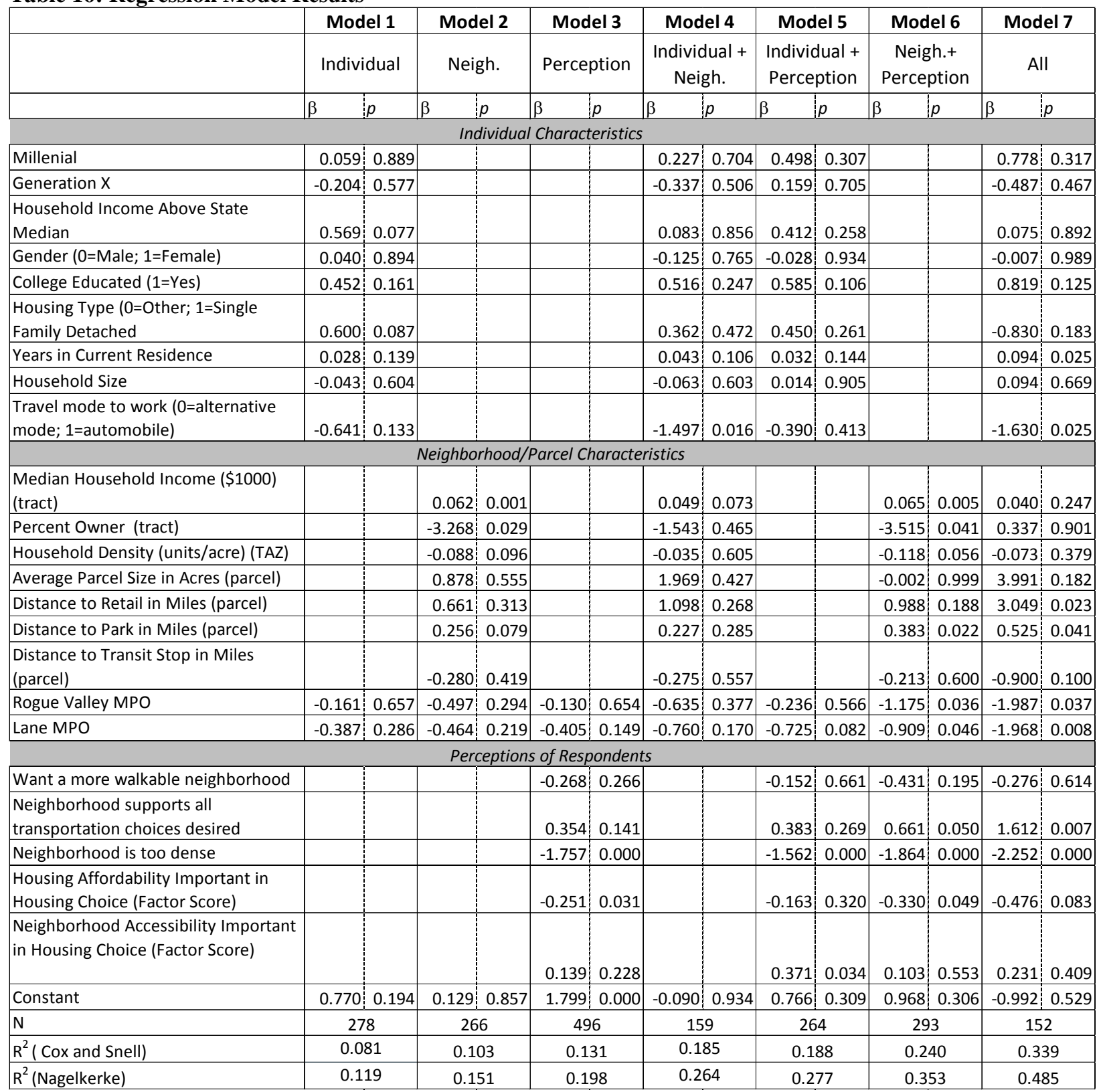

\subsubsection{Summary}

The authors draw several conclusions from the regression analysis. Not surprisingly, density has a negative effect on perceptions of livability. What is interesting about this result is that the perception of a neighborhood being too dense is statistically significant in all the models it was used in and is more influential than objective measures of density (housing units per acre or lot size).

The results show interesting perceptions among respondents by generation. When controlling for other characteristics like income, Millennials see neighborhoods as more livable than Boomers and Boomers more livable than Gen-Xers. The results suggest that individuals weigh tradeoffs 
between accessibility and affordability, with housing affordability having a negative effect and accessibility having a positive effect. Income has a weak positive effect, while housing ownership has a stronger positive effect.

One of the interesting results of the analysis is that transportation appears to be more important to perceptions of neighborhood livability than land use or density. While density and small lot sizes negatively impact livability, the perception of a lack of transportation options negatively influences livability. The results suggest that access to transit positively influences perceptions of livability while, counterintuitively, distance to parks and retail show negative effects.

Walkability appears prominently in perceptions of neighborhood livability. Driving to work has a negative impact on livability. Moreover, the results suggest that individuals who are dissatisfied with the mode choices available do not think the neighborhood has all the options they want in their neighborhood and want a more walkable environment.

Finally, the Central Lane and Rogue Valley MPOs both had negative effects on perceptions of livability when compared with the Albany MPO. The Albany MPO has a population less than half the size of the Rogue Valley MPO and about one-quarter the size of the Central Lane MPO. While it is not possible to say that population size explains this result, the results suggest that individuals who live in smaller communities may perceive them as more livable relative to those in larger communities. 



\subsection{CONCLUSIONS}

This research project examined how land use and transportation impact livability in three different MPOs in Oregon. While Oregon has established goals of improving livability in land use and transportation plans, there is limited understanding of how transportation and land use contribute to perceptions of livability. We focused our research on smaller communities outside of the Portland region that have been overlooked in previous studies. Relying on a mixed-mode survey administered to a stratified random sample of registered voters from different density categories, we gauged perceptions of livability and the contributions of land use and transportation. We received an effective response rate of 18\% (537 responses), though some responses were incomplete.

This research provides government agencies and community organizations a broader perspective on which characteristics of the built environment add to or detract from livability, or what is sometimes referred to as the "good community." For instance, what does a livable community look like? Is it possible to measure livability objectively? What do residents consider livable and how do these perceptions differ from local and state agency conceptions? Finally, how can local and state governments achieve the objective of creating livable communities? These questions provide the foundation for this research.

Our regression analysis revealed the perceptions were more influential than objective (GIS) or sociodemographic measures. This finding mirrors previous literature which has found that perceptions are the most influential determinants of satisfaction when controlling for sociodemographic characteristics.

Some of our findings offer interesting insights into the determinants of livability. We found that people trade off affordability and livability. When people said that housing affordability was more important in decisions about housing and neighborhood choice, they had more negative perceptions of livability in their neighborhood. But people who prioritize accessibility have a more positive perception of livability. This finding warrants further investigation into the intersection with neighborhood choice and income.

Sociodemographics of individuals and neighborhoods showed interesting and unexpected results. Generation (age) affects perceptions of livability. While Boomers seem to have more positive perceptions of livability overall in the descriptive data, when we controlled for socioeconomic status Millennials saw neighborhoods as more livable than Boomers and Boomers saw neighborhoods as more livable than Generation X. As we expected, higher-income neighborhoods were more livable than lower-income neighborhoods but, surprisingly, neighborhoods with a higher share of owner-occupied housing were perceived as less livable. The following table conveys the direction of the influence of objective and subjective measures on perception of livability. This table summarizes findings from descriptive analysis and regression analysis. We organized the table around measures of housing choice, urban form, transportation and amenities (like access to parks and services.) 


\begin{tabular}{|c|c|c|}
\hline & Positive & Negative \\
\hline \multirow[t]{4}{*}{$\begin{array}{l}\text { Housing } \\
\text { Choice }\end{array}$} & $\begin{array}{l}\text { Prioritizing accessibility in } \\
\text { housing/neighborhood } \\
\text { choice }\end{array}$ & $\begin{array}{l}\text { Prioritizing affordability in } \\
\text { housing/neighborhood } \\
\text { choice }\end{array}$ \\
\hline & Affordability & \\
\hline & Safety & \\
\hline & Dwelling characteristics & \\
\hline \multirow{4}{*}{ Urban Form } & Sidewalks & Mixed use near homes \\
\hline & Street trees & Density \\
\hline & $\begin{array}{l}\text { Mix of retail, residential } \\
\text { and services }\end{array}$ & $\begin{array}{l}\text { Perception that } \\
\text { neighborhood is too dense }\end{array}$ \\
\hline & Quality housing & \\
\hline \multirow[t]{3}{*}{ Transportation } & Variety of options & $\begin{array}{l}\text { Lack of desired } \\
\text { transportation options }\end{array}$ \\
\hline & Pedestrian options & Driving to work \\
\hline & $\begin{array}{l}\text { Sidewalks, trees, } \\
\text { crosswalks }\end{array}$ & \\
\hline \multirow[t]{2}{*}{ Amenities } & Proximity to parks $(\sim)$ & Proximity to retail \\
\hline & $\begin{array}{l}\text { Proximity to grocery } \\
\text { stores }\end{array}$ & \\
\hline
\end{tabular}

The research has several implications. First, access to transportation options is important in descriptive and regression analysis. More specifically, individuals who reported better access to transportation options across a broad range of measures reported higher ratings of livability. Pedestrian improvements and natural amenities were important to survey respondents. This suggests that to improve livability, local governments seek balanced transportation options including investments in non-auto-centric modes - particularly pedestrian infrastructure. While the results suggest transportation options improve perceptions of livability, it is important to note that those options should not exclude automobile or vehicular options - $86 \%$ of survey respondents indicated this was important in their ideal neighborhood.

The findings, however, suggest challenges with transit. Regression results show a positive relationship between distance to transit stops and livability (e.g., closer transit stops relate to higher perceptions of livability). But, the results suggest that residents may not be tolerant of the densities needed to support alternative modes.

One of the core objectives of this research was to better understand how density relates to perceptions of livability. As a general observation, most respondents did not accurately indicate the actual density of the neighborhood they live in. In fact, $28 \%$ indicated the correct density range, while $53 \%$ of respondents indicated perceived densities that were higher than the actual density. Nineteen percent of respondents indicated perceived densities that were lower than the actual density in their neighborhood. 
Many communities face ongoing issues with housing affordability, and research increasingly points to zoning codes and NIMBYism as key contributors. The results suggest that density alone does not improve livability and has a negative impact on perceptions of livability. As other studies have shown, density needs to be combined with other services and accessibility to improve livability.

In short, people don't understand density within their neighborhoods. The implications are that local and state government should attempt to educate citizens about what density looks like. Researchers should continue to conduct research that gets at the root causes of these perceptions, which may be more strongly related to income and housing tenure than density. People trade off affordability for livability. Affordable housing policy should focus on making more livable neighborhoods accessible to all income groups. 



\subsection{REFERENCES}

Adams, Richard E. 1992. "Is Happiness a Home in the Suburbs?: The Influence of Urban versus Suburban Neighborhoods on Psychological Health.” Journal of Community Psychology 20 (4): 353-72. https://doi.org/10.1002/1520-6629(199210)20:4<353::AIDJCOP2290200409>3.0.CO;2-Z.

Anguelovski, I. (2015). Tactical Developments for Achieving Just and Sustainable Neighborhoods: The Role of Community-Based Coalitions and Bottom-to-Bottom Networks in Street, Technical, and Funder Activism. Retrieved from Environment \& Planning C: Government \& Policy, 33, 4: 703-725.

Allen, NM. (2016). Quality of Urban Life and Intensification: Understanding Housing Choices, Trade-Offs, and the Role of Urban Amenities. PhD Dissertation: University of Auckland.

Appleyard, Bruce S. (2005). Livable Streets for School Children, NCBW Forum Article 3-7-05. http://www.bikewalk.org/pdfs/forumarch0305.pdf

Appleyard, B., Ferrell, C., Carroll, M., \& Taecker. (2014). Toward Livability Ethics: A Framework to Guide Planning, Design, and Engineering Decisions. Retrieved from Journal of the

Appleyard, B., Ferrell, C., Taecker, M. (2017). Transit Corridor Livability: Realizing the Potential of Transportation and Land Use Integration. Retrieved from http://docs.trb.org/prp/17-03490.pdf Transportation Research Board, 2403, 62-71.

Arundel, Rowan, and Richard Ronald. 2017. "The Role of Urban Form in Sustainability of Community: The Case of Amsterdam.” Environment and Planning B: Urban Analytics and City Science 44 (1): 33-53. https://doi.org/10.1177/0265813515608640.

Bagley, Michael N., Patricia L. Mokhtarian, and Ryuichi Kitamura. 2002. "A Methodology for the Disaggregate, Multidimensional Measurement of Residential Neighbourhood Type.” Urban Studies 39 (4): 689-704.

Baker, S. \& Biton, A. (2015). Changing the Landscape of Livability. Retrieved from Public Roads, 79, 1: 24-31.

Balsas, C. (2004). Measuring the Livability of an Urban Center: An Explanatory Study of Key Performance Indicators. Retrieved from Planning, Practice \& Research, 19, 1: 101-110.

Beatley, T. (2000). Green urbanism: Learning from European cities. Washington, DC: Island Press.

Beatley, T., and Manning, K. (1997). The ecology of place: Planning for environment, economy, and community. Washington, DC: Island Press.

Bonnes, Mirilia, Marino Bonaiuto, and Anna Paola Ercolani. 1991. "Crowding and Residential Satisfaction in the Urban Environment: A Contextual Approach.” Environment and Behavior 23 (5): 531-52. https://doi.org/10.1177/0013916591235001.

Bramley, Glen, Nicola Dempsey, Sinead Power, Caroline Brown, and David Watkins. 2009. "Social Sustainability and Urban Form: Evidence from Five British Cities.” Environment and Planning A 41 (9): 2125-42. https://doi.org/10.1068/a4184.

Buys, Laurie, and Evonne Miller. 2012. "Residential Satisfaction in Inner Urban Higher-Density Brisbane, Australia: Role of Dwelling Design, Neighbourhood and Neighbours.” Journal of Environmental Planning and Management 55 (3): 319-38. 
https://doi.org/10.1080/09640568.2011.597592.

Campbell, Angus, Philip E. Converse, and Willard L. Rodgers. 1986. The Quality of American

Life: Perceptions, Evaluations, and Satisfactions. New York: Russell Sage Foundation. https://www.russellsage.org/publications/quality-american-life.

Cao, Xinyu (Jason). 2016. "How Does Neighborhood Design Affect Life Satisfaction? Evidence from Twin Cities.” Travel Behaviour and Society, Planning for quality of life, 5 (Supplement C): 68-76. https://doi.org/10.1016/j.tbs.2015.07.001.

Carp, Frances M., Rick T. Zawadski, and Hossein Shokrkon. 1976. “Carp 1976.” Environment and Behavior 8 (2). http://journals.sagepub.com/doi/pdf/10.1177/001391657682004.

Chapman, N. \& Lund, H. (2004). Housing Density and Livability in Portland. Retrieved from The Portland Edge: Challenges and Successes in Growing Communities, Chapter 10.

Chilcoat, C. (2014). Not in my Backyard. Retrieved from http://www.pennenergy.com/articles/pennenergy/2014/02/oil-and-gas-not-in-mybackyard.html

Chinnam, R., Murat, A. (2016, August 31). Community-Aware Charging Station Network Design for Electrified Vehicles in Urban Areas: Reducing Congestion, Emissions, Improving Accessibility, and Promoting Walking, Bicycling, and use of Public Transportation. Retrieved from http://www.wmich.edu/sites/default/files/attachments/u883/2016/TRCLC_15_08_Report. pdf

Chen, Li, Wenzhong Zhang, Yizhao Yang, and Jianhui Yu. 2013. "Disparities in Residential Environment and Satisfaction among Urban Residents in Dalian, China.” Habitat International 40 (Supplement C): 100-108. https://doi.org/10.1016/j.habitatint.2013.03.002.

Cook, Christine C. 1988. "Components of Neighborhood Satisfaction: Responses from Urban and Suburban Single-Parent Women.” Environment and Behavior 20 (2): 115-49. https://doi.org/10.1177/0013916588202001.

Coughlin, J. F. (2007). Disruptive Demographics, Design, and the Future of Everyday Environments. Retrieved from Design Management Review, 18, 2: 53-59.

Coughlin, J. F. \& Proulx, S. (2012). If Demographics is Destiny, Are We Preparing for It? Aging Baby Boomers, Transportation Planning, and Investing in Mobility Tomorrow. Retrieved from Aging America and Transportation: Personal Choices and Public Policy, Chapter 14.

Dekker, Karien, Sjoerd de Vos, Sako Musterd, and Ronald van Kempen. 2011. "Residential Satisfaction in Housing Estates in European Cities: A Multi-Level Research Approach.” Housing Studies 26 (04): 479-99. https://doi.org/10.1080/02673037.2011.559751.

DLCD. (2000). Inside the Boundaries, Oregon Department of Land Conservation and Development.

Duany, A. and Talen, E. (2002). Transect planning, Journal of the American Planning Association, 68, 245-266.

Dumbaugh, E. \& Li, W. (2010). Designing for the Safety of Pedestrians, Cyclists, and Motorists in Urban Environments. Retrieved from Journal of the American Planning Association, 77, 1: 69-88.

Fischer, E. (2000). Building Livable Communities for the 21st Century. Retrieved from Public Roads, 63, 6: 30-34. 
Friedman, S., and Rosenbaum, E. (2004). Nativity status and racial/ethnic differences in access to quality housing: Does homeownership bring greater parity. Housing Policy Debate 15(4): 865-901.

Geller, A. L. (2003). Smart growth: A prescription for livable cities. American Journal of Public Health, 93(9), 1410-5. Retrieved from http://libproxy.uoregon.edu/login?url=http://search.proquest.com/docview/215095173?ac countid=14698

Grogan-Kaylor, Andrew, Michael Woolley, Carol Mowbray, Thomas M. Reischl, Megan Gilster, Rebecca Karb, Peter Macfarlane, Larry Gant, and Katherine Alaimo. 2006. "Predictors of Neighborhood Satisfaction." Journal of Community Practice 14 (4): 2750. https://doi.org/10.1300/J125v14n04_03.

Grau, Dieter. (n.d.). A Way to Overcome Urban Water Crisis and Creating Livable Cities. http://www.dreiseitl.com/data/PUBLICATIONS/12_INL_DG_A_Way_to_Overcome_Ur ban_Water_Crisis_and_Creating_Livable_Cities.pdf

Godavarthy, R., Mattson, J. (2016, November). Exploring Transit's Contribution to Livability in Rural Communities: Case Study of Valley City, ND, and Dickinson, ND. Retrieved from http://www.ugpti.org/resources/reports/downloads/surlc16-004.pdf

Godschalk, D. R. (2007). Land Use Planning Challenges: Coping with Conflicts in Visions of Sustainable Development and Livable Communities. Retrieved from Journal of the American Planning Association, 70, 1: 5-13.

Gruber, Kenneth J., and Gladys G. Shelton. 1987. "Assessment of Neighborhood Satisfaction by Residents of Three Housing Types.” Social Indicators Research 19 (3): 303-315.

Guzman, S. \& Douglas, A. (2015). Livability for All. Retrieved from American Planning Association: 21-24.

Haarhoff, Errol, Lee Beattie, and Ann Dupuis. 2016. "Does Higher Density Housing Enhance Liveability? Case Studies of Housing Intensification in Auckland.” Edited by Ben Derudder. Cogent Social Sciences 2 (1): 1243289. https://doi.org/10.1080/23311886.2016.1243289.

Hardy, D., Hunter, B. (2017). Balancing Goods Movement and Livability with Freight Roadway Design Considerations. Retrieved from http://docs.trb.org/prp/17-01016.pdf

Harrell, R., Lynott, J., \& Guzman, S. (2014). What is Livable? Community Preferences of Older Adults. Retrieved from AARP Public Policy Institute: 1-43.

Harvey, C. \& Aultman-Hall, L. (2016). Measuring Urban Streetscapes for Livability: A Review of Approaches. Professional Geographer, 68, 1: 149-158.

Heatwole-Shank, K. S. \& Cutchin, M. P. (2016). Processes of Developing 'Community Livability’ in Older Age. Journal of Aging Studies, 39: 66-72.

Howley, Peter, Mark Scott, and Declan Redmond. 2009. "Sustainability versus Liveability: An Investigation of Neighbourhood Satisfaction.” Journal of Environmental Planning and Management 52 (6): 847-64. https://doi.org/10.1080/09640560903083798.

Hur, Misun, and Hazel Morrow-Jones. 2008. "Factors That Influence Residents' Satisfaction With Neighborhoods.” Environment and Behavior 40 (5): 619-35. https://doi.org/10.1177/0013916507307483.

Hur, Misun, Jack L. Nasar, and Bumseok Chun. 2010. “Neighborhood Satisfaction, Physical and Perceived Naturalness and Openness.” Journal of Environmental Psychology 30 (1): 5259. https://doi.org/10.1016/j.jenvp.2009.05.005. 
Jim, C. (2003). Protection of Urban Trees from Trenching Damage in Compact City Environments. Retrieved from Cities, 20, 2: 87-94.

Kaal, H. (2011). A Conceptual History of Livability. Retrieved from City, 15, 5: 532-547.

Kearney, Anne R. 2006. "Residential Development Patterns and Neighborhood Satisfaction: Impacts of Density and Nearby Nature.” Environment and Behavior 38 (1): 112-39. https://doi.org/10.1177/0013916505277607.

Kihl, M., Brennan, D., List, J., \& Mittal, P. (2005). Livable Communities: An Evaluation Guide. Retrieved from https://assets.aarp.org/rgcenter/il/d18311_communities.pdf

Kindsatter, D., d’Amato, A., McLaughlin, S. (2017). Measuring the Success of Urban Viaduct Removal Projects. Retrieved from https://trid.trb.org/View/1437151

Larco, N. (2009). Untapped Density: Site Design and the Proliferation of Suburban Multifamily Housing. Retrieved from Journal of Urbanism: International Research on Placemaking and Urban Sustainability, 2, 2: 167-186.

Lee, Suzanna M., Terry L. Conway, Lawrence D. Frank, Brian E. Saelens, Kelli L. Cain, and James F. Sallis. 2017. "The Relation of Perceived and Objective Environment Attributes to Neighborhood Satisfaction.” Environment and Behavior 49 (2): 136-60. https://doi.org/10.1177/0013916515623823.

Li, Yanmei, Mary V. Wenning, and Hazel A. Morrow-Jones. 2013. “Differences in Neighborhood Satisfaction Between African American and White Homeowners During the Early 2000s.” Housing and Society 40 (2): 124-49. https://doi.org/10.1080/08882746.2013.11430613.

Li, Y. (2012). Neighborhood amenities, satisfaction, and perceived livability of foreign-born and native-born U.S. residents. Journal of Identity and Migration Studies, 6(1), 115-137,167. Retrieved from http://libproxy.uoregon.edu/login?url=http://search.proquest.com/docview/1432710761?a ccountid $=14698$

Lovejoy, Kristin, Susan Handy, and Patricia Mokhtarian. 2010. "Neighborhood Satisfaction in Suburban versus Traditional Environments: An Evaluation of Contributing Characteristics in Eight California Neighborhoods.” Landscape and Urban Planning 97 (1): 37-48. https://doi.org/10.1016/j.landurbplan.2010.04.010.

Lu, Max. 1999. "Determinants of Residential Satisfaction: Ordered Logit vs. Regression Models.” Growth and Change 30 (2): 264-87. https://doi.org/10.1111/0017-4815.00113.

Mahmoudi, M., Ahmad, F., \& Abbasi, B. (2015). Livable Streets: The Effects of Physical Problems on the Quality and Livability of Kuala Lumpur Streets. Retrieved from Cities, 43: 104-114.

Marshall, W., and McAndrews, C. n.d. "Does the Livability of a Residential Street Depend on the Characteristics of the Neighboring Street Network?” Accessed January 2, 2018. https://www.ugpti.org/resources/reports/downloads/mpc16-309.pdf.

McAndrews, Carolyn, and Wesley Marshall. 2018. "Livable Streets, Livable Arterials? Characteristics of Commercial Arterial Roads Associated With Neighborhood Livability.” Journal of the American Planning Association 84 (1): 33-44. https://doi.org/10.1080/01944363.2017.1405737.

McCrea, Rod, Tung-Kai Shyy, and Robert J. Stimson. 2014. "Satisfied Residents in Different Types of Local Areas: Measuring What’s Most Important.” Social Indicators Research 118 (1): 87-101. https://doi.org/10.1007/s11205-013-0406-8.

McCulloch, Andrew. 2012. "Housing Density as a Predictor of Neighbourhood Satisfaction 
among Families with Young Children in Urban England.” Population, Space and Place 18 (1): 85-99. https://doi.org/10.1002/psp.650.

Mekuria, Maaza; Appleyard, Bruce; and Nixon, Hilary (2017). Improving Livability Using Green and Active Modes: A Traffic Stress Level Analysis of Transit, Bicycle, and Pedestrian Access and Mobility, Urban Studies Commons. http://scholarworks.sjsu.edu/cgi/viewcontent.cgi?article=1227\&context=mti_publications

Mouratidis, Kostas. 2017. "Is Compact City Livable? The Impact of Compact versus Sprawled Neighbourhoods on Neighbourhood Satisfaction.” Urban Studies, October, 0042098017729109. https://doi.org/10.1177/0042098017729109.

Newsome, T., P.H.D., \& Pleasant, D., A.I.C.P. (2014). Transit and complete streets helping to create the next charlotte. Institute of Transportation Engineers. ITE Journal, 84(2), 21-5. Retrieved from http://libproxy.uoregon.edu/login?url=http://search.proquest.com/docview/1498090359?a ccountid $=14698$

Ortegon-Sanchez, A., Popan, C., Tyler, N. (2017). Car-Free Initiatives from Around the World: Concepts for Moving to Future Sustainable Mobility. Retrieved from http://docs.trb.org/prp/17-06816.pdf

Parkes, Alison, Ade Kearns, and Rowland Atkinson. 2002. "What Makes People Dissatisfied with Their Neighbourhoods?” Urban Studies 39 (13): 2413-38. https://doi.org/10.1080/0042098022000027031.

Parker, Robert; Lewis, Rebecca; Moore, Terry; Kato Ken (2015). Analysis of Land Use Efficiency in Oregon Cities: A Report to the HB 2254 Rules Advisory Committee.

Pelley, J. (1999). Livability agenda may be unable to encourage smart growth. Environmental Science Technology, 33(9), 190A. Retrieved from http://pubs.acs.org/doi/abs/10.1021/es992791e

Permentier, Matthieu, Gideon Bolt, and Maarten van Ham. 2011. "Determinants of Neighbourhood Satisfaction and Perception of Neighbourhood Reputation.” Urban Studies 48 (5): 977-96. https://doi.org/10.1177/0042098010367860.

Pojani, D., Stead, D. (2014). Ideas, interests, and institutions: Explaining Dutch transit-oriented development challenges. Environment and Planning A, 46(10), 2401-18. Retrieved from http://journals.sagepub.com/doi/abs/10.1068/a130169p

Pokharel, Sanjay; Shinstine, Debbie; and Ksaibati, Khaled. (2014). Developing a Livability Program for Indian Reservations: A Methodology and Case Study, Transportation Research Board. http://docs.trb.org/prp/15-0939.pdf

Riggs, W., Gilderbloom, J. (2017). The Economic and Social Impact of One-Way Street Design and Performance on Neighborhood Livability. Retrieved from https://trid.trb.org/View/1439700

Rodgers, Willard L. 1982. "Density, Crowding, and Satisfaction with the Residential Environment.” Social Indicators Research 10 (1): 75-102.

Rohe, W. (2009). From Local to Global: One Hundred Years of Neighborhood Planning. Retrieved from Journal of the American Planning Association, 75, 2: 209-230.

Rosenthal, L. (2009). The Role of Local Government: Land-Use Controls and AgingFriendliness. Retrieved from Generations, 33, 2: 18-25.

Ruth, M. \& Franklin, R. S. (2014). Livability for All? Conceptual Limits and Practical Implications. Retrieved from Applied Geography, 49: 18-23.

Savonis, M. (2013). Fitting Livability into a Sustainability Framework. Retrieved from TR News, 288: 11. 
Silverstein, N. M., Johns, E., \& Griffin, J. A. (2008). Students Explore Livable Communities. Retrieved from Gerontology \& Geriatrics Education, 29, 1: 19-37.

Toan, K. (2015). Not Under my Backyard: The Battle between Colorado and Local Governments over Hydraulic Fracturing. Retrieved from Colorado Natural Resources, Energy \& Environmental Law Review, 26, 1: 1-68.

Van Dyck, Delfien, Greet Cardon, Benedicte Deforche, and Ilse De Bourdeaudhuij. 2011. “Do Adults like Living in High-Walkable Neighborhoods? Associations of Walkability Parameters with Neighborhood Satisfaction and Possible Mediators.” Health \& Place 17 (4): 971—977. https://doi.org/10.1016/j.healthplace.2011.04.001.

Walton, D., S. J. Murray, and J. A. Thomas. 2008. "Relationships Between Population Density and the Perceived Quality of Neighbourhood.” Social Indicators Research 89 (3): 40520. https://doi.org/10.1007/s11205-008-9240-9.

Wheeler, M. (1993). Regional Consensus on Affordable Housing: Yes in my Backyard? Journal of Planning Education and Research, 12, 1: 139-149.

Yang, Yizhao. 2008. “A Tale of Two Cities: Physical Form and Neighborhood Satisfaction in Metropolitan Portland and Charlotte.” Journal of the American Planning Association 74 (3): 307-23. https://doi.org/10.1080/01944360802215546.

Yang, Yizhao, and Kelly O’Neill. 2014. “Understanding Factors Affecting People’s Attitudes toward Living in Compact and Mixed-Use Environments: A Case Study of a New Urbanist Project in Eugene, Oregon, USA.” Journal of Urbanism: International Research on Placemaking and Urban Sustainability 7 (1): 1-22. https://doi.org/10.1080/17549175.2013.827585. 


\subsection{APPENDIX: SURVEY INSTRUMENT}




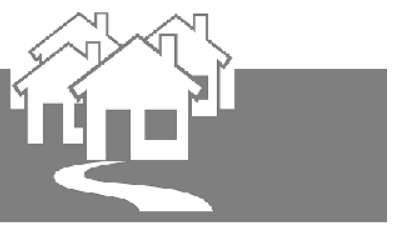

Dear Community Member,

You've been selected to participate in the Oregon Livability Survey! The Oregon Livability Survey is intended to measure citizen perceptions of and preferences for livability.

The term "livability" is frequenty used and promoted by communities across the United States. In Oregon, various local communities, including some state agencies, seek to improve livability. But what is it? The Community Service Center at the University of Oregon wants to know what you think livability is, specifically as it relates to transportation and land use patterns in your neighborhood. This survey will help Oregon governments and organizations better understand your community's needs and preferences.

This survey should take you about 15 to 30 minutes to complete. As an incentive, we will randomly select four participants to win $\$ 50$ gift cards. To enter to win, provide your contact information on the last page of the survey. You do not have to complete the survey to enter the raffle.

There are two ways to provide feedback; choose the survey method that is most convenient to you.

1) Paper Mailer Survey Instructions:

$\square \quad$ This questionnaire should be filled out by the individual in which this survey was addressed to.

$\square$ Carefully read each question and mark your responses.

$\square$ We will not publish or share any personally identifying information that you share with us.*

$\square \quad$ Please complete the survey and retum by mail using the provided envelope by March 27, 2017.

Please record your survey code located on the front on your envelope above your address here: (This will allow us to take your name off our mailing list after you complete the survey)

$$
-\mathrm{OR}-
$$

2) Online Survey Instructions:

口 Visit https://goo.gl/Xedb5C or use the QR Code:

$\square$ This questionnaire should be filled out by the individual in which this survey was addressed to.

$\square$ Carefully read each question and mark your responses.

$\square$ We will not publish or share any of the personally identifying information that you share with us.*

$\checkmark \quad$ Please complete the online survey by March 27, 2017.

*This survey was developed by the University of Oregon's Community Service Center (CSC) in partnership with the University of Oregon and funded through the National Institute of Transportation and Communities. Your answers are and will be completely confidential. Any personally identifying information will not be tied to any product this research produces. We will not share or sell your personally identifying information. By completing and returning this survey you provide consent in allowing the CSC to use these findings for research. You may choose not to participate in this survey without penafty. If you have any questions, please contact Robert Parker, Community Service Center Director (541.346.3801 or rgp@uoregon.edu).

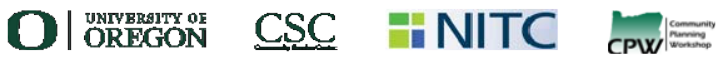




\section{First, we would like to know what you think LIVABILITY is.}

There are no official definitions of livability. One of the goab of this survey is to gain an understanding of resident perceptions of livability. In this survey, we ask questions about your IDEAL neighbohood and about your CURRENT neighbohood. Your IDEAL neighborhood is where you would like to live and your CURRENT neighborhood is where you currently live. For some respondents, your IDEAL neighbohood and CURRENT neighbohood may be the same. A neighborhood is defined as anything within a 20-minute walk of your home.

Q1 How SATSFIED or DISSATISFIED are you with your current house/home, neighborhood, city, region, and state?

Consider "neighborhood" as everything within a 20 minute walk of your home. Note that the average person can walk about one mile in 20 minutes.

\begin{tabular}{lccccc}
\hline Geographic Levels: & $\begin{array}{c}\text { Extremely } \\
\text { satisfied }\end{array}$ & $\begin{array}{c}\text { Somewhat } \\
\text { satisfied }\end{array}$ & $\begin{array}{c}\text { Neither } \\
\text { satisfied nor } \\
\text { dissatisfied }\end{array}$ & $\begin{array}{c}\text { Somewhat } \\
\text { dissatisfied }\end{array}$ & $\begin{array}{c}\text { Extremely } \\
\text { dissatisfied }\end{array}$ \\
\hline House/Home & $\square$ & $\square$ & $\square$ & $\square$ & $\square$ \\
Your neighborhood & $\square$ & $\square$ & $\square$ & $\square$ & $\square$ \\
Your city & $\square$ & $\square$ & $\square$ & $\square$ & $\square$ \\
Your county & $\square$ & $\square$ & $\square$ & $\square$ & $\square$ \\
Oregon & $\square$ & $\square$ & $\square$ & $\square$ & $\square$ \\
\hline
\end{tabular}

Q2 Rate the following factors in level of importance for selecting your current home or neighborhood.

\begin{tabular}{|c|c|c|c|c|c|}
\hline Characteristics: & $\begin{array}{l}\text { Extremely } \\
\text { important }\end{array}$ & $\begin{array}{l}\text { Somewhat } \\
\text { important }\end{array}$ & $\begin{array}{c}\text { Neither } \\
\text { important } \\
\text { nor } \\
\text { unimportant }\end{array}$ & $\begin{array}{l}\text { Somewhat } \\
\text { unimportant }\end{array}$ & $\begin{array}{c}\text { Extremely } \\
\text { unimportant }\end{array}$ \\
\hline Proximity to neighbors & $\square$ & $\square$ & $\square$ & $\square$ & $\square$ \\
\hline $\begin{array}{l}\text { Proximity to parks or open } \\
\text { space }\end{array}$ & $\square$ & $\square$ & $\square$ & $\square$ & $\square$ \\
\hline Proximity to family members & $\square$ & $\square$ & $\square$ & $\square$ & $\square$ \\
\hline Distance to work or school & $\square$ & $\square$ & $\square$ & $\square$ & $\square$ \\
\hline Distance to retail/services & $\square$ & $\square$ & $\square$ & $\square$ & $\square$ \\
\hline Affordability & $\square$ & $\square$ & $\square$ & $\square$ & $\square$ \\
\hline $\begin{array}{l}\text { Access to transportation } \\
\text { options (i.e. ability to walk, } \\
\text { bike or take the bus to } \\
\text { destinations) }\end{array}$ & $\square$ & $\square$ & $\square$ & $\square$ & $\square$ \\
\hline Crime levels & $\square$ & $\square$ & $\square$ & $\square$ & $\square$ \\
\hline School quality & $\square$ & $\square$ & $\square$ & $\square$ & $\square$ \\
\hline $\begin{array}{l}\text { Neighborhood characteristics } \\
\text { (i.e. homes of a similar style v. } \\
\text { variety of types, historic } \\
\text { homes) }\end{array}$ & $\square$ & $\square$ & $\square$ & $\square$ & $\square$ \\
\hline $\begin{array}{l}\text { House characteristics (i.e. } \\
\text { number of bedrooms, } \\
\text { accessibility, etc.) }\end{array}$ & $\square$ & $\square$ & $\square$ & $\square$ & $\square$ \\
\hline
\end{tabular}

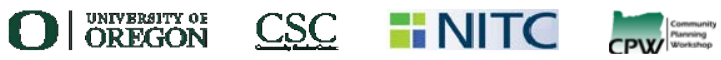




$$
\text { 1: }
$$

Q4 Would the words you listed in Q3 be the same words you would use to describe your IDEAL LIVABLE CITY?

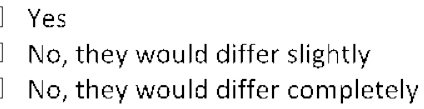

\begin{tabular}{lcccc}
\hline Geographic Levels: & Excellent & Good & Fair & Poor \\
\hline House/Home & $\square$ & $\square$ & $\square$ & $\square$ \\
Your neighborhood & $\square$ & $\square$ & $\square$ & $\square$ \\
Your city & $\square$ & $\square$ & $\square$ & $\square$ \\
Your county & $\square$ & $\square$ & $\square$ & $\square$ \\
Oregon & $\square$ & $\square$ & $\square$ & $\square$ \\
\hline
\end{tabular}

\section{Next, we would like to know how TRANSPORTATION and LAND USE influences your perception of livability at the neighborhood level.}

$\square$ Very little foot traffic. No activities with a 20 -minute walk.

Moderate foot traffic intermittently. Some activities within a 20 -minute walk.

Heavy foot traffic. Many activities available day and night.

Q7 Based on your response to Q6, what does your CURRENT NEIGHBORHOOD resemble?

Very little foot traffic. No activities with a 20 -minute walk.

Moderate foot traffic intermittently. Some activities within a 20 -minute walk.

Heavy foot traffic. Many activities available day and night.

Q8

Where would you prefer to see parking in your IDEAL NEIGHBORHOOD? (check all that apply)

$\square$ Driveways

$\square$ Along the street

$\square$ Personal garage

$\square$ Behind the house
Parking lots in front of buildings

Parking lots on side of buildings

Parking lots behind buildings

Parking garage 


\begin{tabular}{|c|c|c|c|c|c|}
\hline & $\begin{array}{l}\text { Extremely } \\
\text { important }\end{array}$ & $\begin{array}{l}\text { Somewhat } \\
\text { important }\end{array}$ & $\begin{array}{c}\text { Neither } \\
\text { important nor } \\
\text { unimportant }\end{array}$ & $\begin{array}{l}\text { Somewhat } \\
\text { unimportant }\end{array}$ & $\begin{array}{l}\text { Extremely } \\
\text { unimportant }\end{array}$ \\
\hline $\begin{array}{l}\text { Presence of Building Diversity in } \\
\text { Style/Design }\end{array}$ & $\square$ & $\square$ & $\square$ & $\square$ & $\square$ \\
\hline $\begin{array}{l}\text { Presence of Buildings in a } \\
\text { Similar Style/Design }\end{array}$ & $\square$ & $\square$ & $\square$ & $\square$ & $\square$ \\
\hline $\begin{array}{l}\text { Presence of Building with } \\
\text { Similar Heights }\end{array}$ & $\square$ & $\square$ & $\square$ & $\square$ & $\square$ \\
\hline $\begin{array}{l}\text { Presence of Buildings Setback at } \\
\text { least } 10 \text { feet from Street }\end{array}$ & $\square$ & $\square$ & $\square$ & $\square$ & $\square$ \\
\hline Presence of Quality Housing & $\square$ & $\square$ & $\square$ & $\square$ & $\square$ \\
\hline Presence of Wide Roads/Streets & $\square$ & $\square$ & $\square$ & $\square$ & $\square$ \\
\hline Presence of Sidewalks & $\square$ & $\square$ & $\square$ & $\square$ & $\square$ \\
\hline $\begin{array}{l}\text { Presence of Short Blocks } \\
\text { (Length) }\end{array}$ & $\square$ & $\square$ & $\square$ & $\square$ & $\square$ \\
\hline $\begin{array}{l}\text { Presence of Street Layout on a } \\
\text { Grid }\end{array}$ & $\square$ & $\square$ & $\square$ & $\square$ & $\square$ \\
\hline Presence of Culs-de-sac & $\square$ & $\square$ & $\square$ & $\square$ & $\square$ \\
\hline Presence of Public spaces & $\square$ & $\square$ & $\square$ & $\square$ & $\square$ \\
\hline $\begin{array}{l}\text { Presence of Natural } \\
\text { Features/Biodiversity }\end{array}$ & $\square$ & $\square$ & $\square$ & $\square$ & $\square$ \\
\hline Presence of Tree-Lined Streets & $\square$ & $\square$ & $\square$ & $\square$ & $\square$ \\
\hline $\begin{array}{l}\text { Presence of Physical Boundary } \\
\text { or Border in Neighborhood } \\
\text { (e.g. river, park or arterial) }\end{array}$ & $\square$ & $\square$ & $\square$ & $\square$ & $\square$ \\
\hline Other: & $\square$ & $\square$ & $\square$ & $\square$ & $\square$ \\
\hline
\end{tabular}

Q14 How important is it that various elements (see examples in Q13) in your neighborhood are visually interesting? (i.e. that elements encompass design/architectural features)

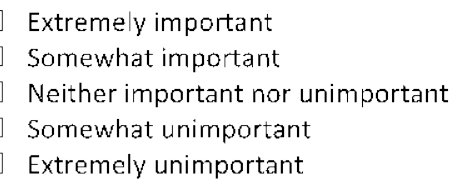

\section{Next, we would like to understand your preferences of livability as it relates to YOUR RESIDENCE AND NEIGHBORHOOD.}

Q15 How would you describe your CURRENT home?

No private outdoor space, possible shared space

$\square$ Small private courtyard, patio, or balcony

Small private yard $\square$ Medium sized private yard separating home from neighbor

$\square$ Large private yard

$\square$ Acreage

$\square$ Other: 
No private outdoor space, possible shared space

Small private courtyard, patio, or balcony

$\square$ Small private yard

$\square$ Medium sized private yard separating home from neighbor
Large private yard

Acreage

$\square$ Other:

How would you classify the building in which you CURRENTLY live?

Single-Family Detached Home

Single-Family Attached Home(i.e. townhome or condo)

Two to Four Apartments
Five to Nine Apartments

Ten or More Apartments

Mobile Home or Other Type of Housing

Q18 How would you classify the building in which you would IDEALLY live?
Single-Family Detached Home
Single-Family Attached Home (i.e. townhome or condo)
Five to Nine Apartments
Ten or More Apartments
$\square$ Mobile Home or Other Type of Housing
Two to Four Apartments
No preference

Q19

In your opinion, would you characterize your CURRENT NEIGHBORHOOD as too dense?
Yes
No
Don't know

Q20 In your opinion, how dense is your CURRENT NEIGHBORHOOD compared to the rest of your city?
High/Nery Dense
Medium/Moderately Dense
Low/Not Dense

Q21 How dense do you think your CURRENT NEIGHBORHOOD is? (Note: an acre is about the size of a football field)

0 to 1 housing units/acre
1 to 3 housing units/acre
3 to 6 housing units/acre

6 to 12 housing units/acre

$12+$ housing units/acre

\section{Please share your perceptions about transportation options.}

Q22 What kind of transportation options would you want in your IDEAL NEIGHBORHOOD? (check all that apply)
Auto/Vehicular Options
$\square$ Public Transit: Cable/Wire-Propelled Option (light rail)
Pedestrian Options
$\square$ Intercity Rail and Bus (i.e. Amtrak, Greyhound, etc.)
Bicycle Options
$\square$ Carsharing Options \{i.e. ZipCar)
$\square$ Public Transit: City Bus 
Q23 Indicate the mode of transportation that you use MOST FREQUENTLY to get to the various places listed below in a typical week.

\begin{tabular}{lccccc}
\hline & $\begin{array}{c}\text { Automobile } \\
\text { /Carpool }\end{array}$ & Bicycle & Walk & $\begin{array}{c}\text { Bus/Public } \\
\text { Transit }\end{array}$ & $\begin{array}{c}\text { Not } \\
\text { Applicable }\end{array}$ \\
\hline How do you get to work? & $\square$ & $\square$ & $\square$ & $\square$ & $\square$ \\
How do you get to shopping centers? & $\square$ & $\square$ & $\square$ & $\square$ & $\square$ \\
How do you get to the grocery store? & $\square$ & $\square$ & $\square$ & $\square$ & $\square$ \\
How do you get to parks and open areas? & $\square$ & $\square$ & $\square$ & $\square$ & $\square$ \\
How do you get your children to school? & $\square$ & $\square$ & $\square$ & $\square$ & $\square$ \\
\hline
\end{tabular}

Q24 If the choice was yours (and you were not constrained by distance, time, or finances) what would be your MOST PREFERRED mode of transportation? (Select only one)
$\square$ Automobile
Walking
Bicycle

Q25 Please indicate your level of agreement or disagreement with this statement: "My neighborhood accommodates all of the transportation options I would like."

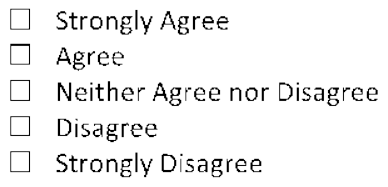

Q26 Please indicate your level of agreement or disagreement with this statement: "I want my neighborhood to be more bicycle/pedestrian-friendly."

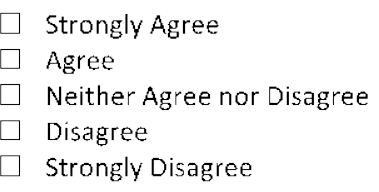

\section{Finally, we would like to know a little bit about you.}

Q27 When was the last time you moved (year)?

Q28 What is your age?

$\square \quad 18-19$ years

20 to 24 years of age

$\square 25$ to 34 years of age

$\square 35$ to 44 years of age $\square 45$ to 54 years of age

$\square 55$ to 64 years of age

$\square 65$ years and over

Q29 What was your annual household income in 2016?
Less that $\$ 15,000$
$\$ 15,000$ to $\$ 24,999$
$\$ 25,000$ to $\$ 34,999$
$\$ 35,000$ to $\$ 49,999$ 
Q31 What is your race/ethnicity?

$\square$ Prefer not to say

White

$\square$ Black, African American

$\square$ Native Hawaiian, Other Pacific Islander
Latino/Hispanic

American Indian, Alaska Native

Asian

Other:

Q32 What zip code do you live in?

Q33 What is the highest degree/level of school you have completed?

$\square$ Less than high school graduate

High school graduate (or equivalency)

$\square$ Some college or associates degree
Bachelor's degree

Graduate degree or higher

Q34 Indicate the number of people in your household.

Number of individuals who are 17 years of age or younger

Number of individuals who are 18 years of age or older

Q35 Do you rent or own the housing unit that you live in currently?
Own
Rent
Occupy without Payment
Prefer not to say

Q36 Finally, indicate the extent to which you agree or disagree with this statement: "My neighborhood is livable."

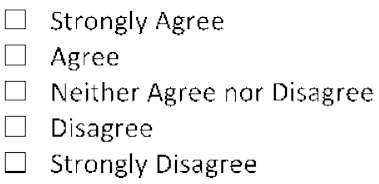

Q37 Is there anything else that you would like to share with us about the concept of livability or your community?

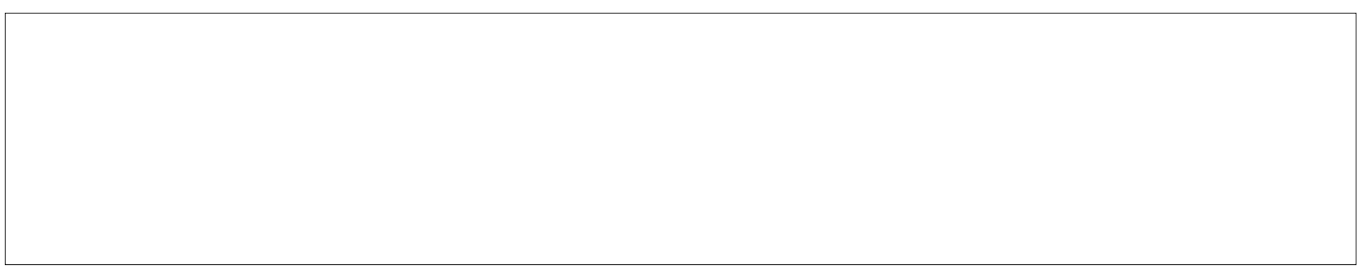

Q38 If you want to be eligible for the raffle or you like to participate in a focus group please provide your email address:

$\square$ Yes, I would like to be contacted to participate in a focus group.

No, thank you.

Not sure, please send me more information.

* Your email address, as well as any identifying information, will not be tied to your responses in any product that this research produces. We will not sell or share any personally identifying information.

\section{Thank you for participating!}



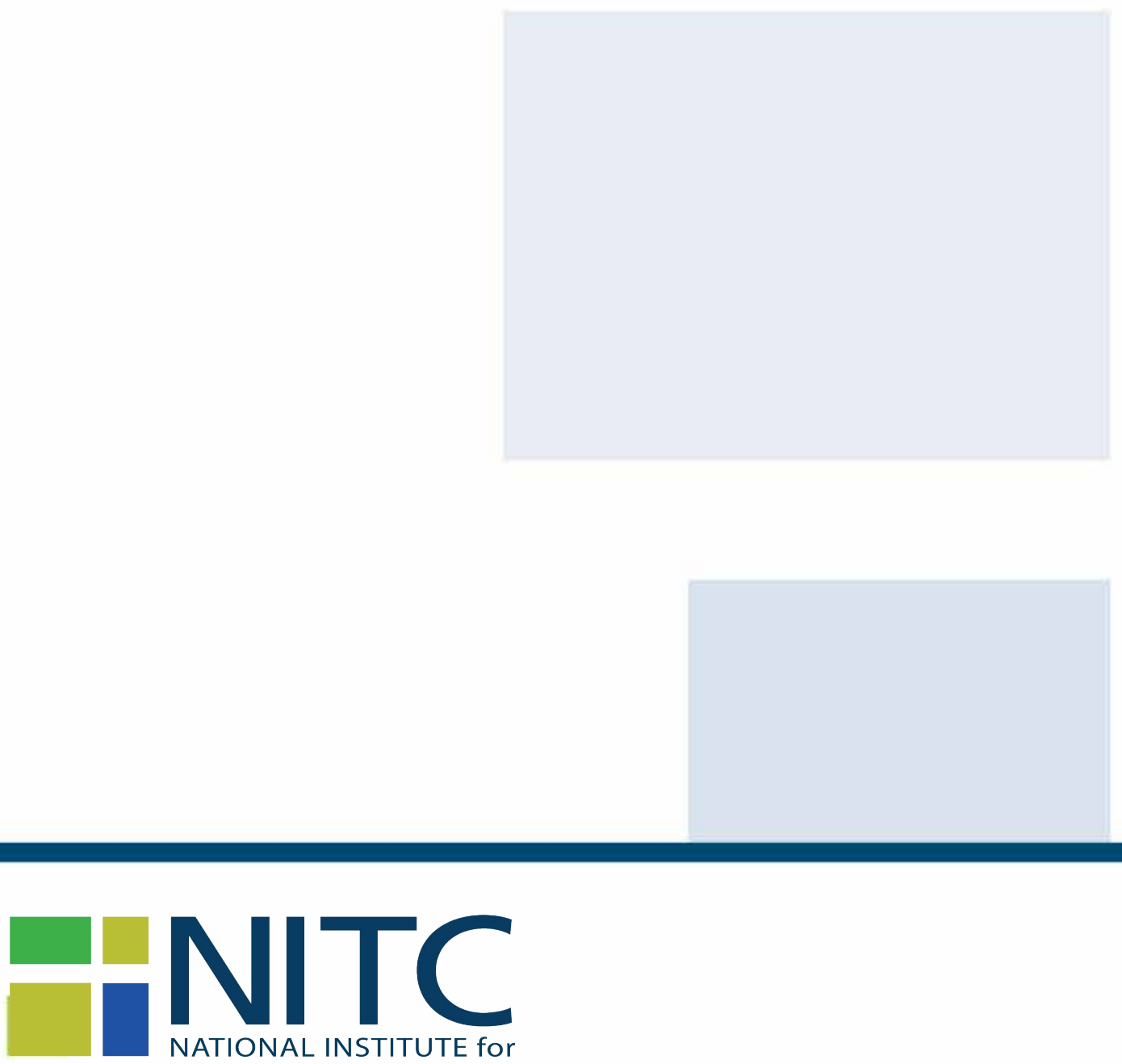

TRANSPORTATION and COMMUNITIES

Transportation Research and Education Center

Portland State University

1900 S.W. Fourth Ave., Suite 175

Portland, OR 97201 